\title{
Application of high hydrophilic antifouling nanofiltration membranes embedded with mesoporous carbon based nanoparticles for efficient dye removal and salt rejection
}

\author{
Azar Asadi ( $\sim$ azarasadi_88@yahoo.com ) \\ Yasouj University Gachsaran Oil and Gas Faculty \\ Foad Gholami \\ Razi University of Kermanshah: Razi University \\ Ali Akbar Zinatizadeh \\ Razi University of Kermanshah: Razi University \\ Hasan Jaberi \\ Azad University: Islamic Azad University
}

\section{Research Article}

Keywords: Nanofiltration membrane, dye and salt rejection, CMK-3 mesoporous, $\mathrm{H}$-acid

Posted Date: August 16th, 2021

DOI: https://doi.org/10.21203/rs.3.rs-742220/v1

License: (c) (1) This work is licensed under a Creative Commons Attribution 4.0 International License.

Read Full License 


\section{Abstract}

In this research, the application of mesoporous carbon CMK-3 and modified CMK-3 (M-CMK-3) to improve antifouling and rejection rate of polyethersulfone NF membrane was assessed. CMK-3 was modified with $\mathrm{H}$-acid to increase hydrophilic characteristics of CMK-3. The synthesized CMK-3 and modified CMK-3 membranes exhibited a high pure water flux and also flux recovery ratio (up to 95\%) compared with bare $\mathrm{NF}$ membrane. Also, the membranes with optimum additive loading $(0.1 \mathrm{wt} \%)$ of CMK-3 and M-CMK-3 were compared to reject different salts and dyes. From the obtained results, the membrane embedded with M-CMK-3 showed higher rejection rate rather than bare NF membrane (up to $95 \%$ for $\mathrm{Na}_{2} \mathrm{SO}_{4}$ and $64 \%$ for $\mathrm{CaCl}_{2}$ ) and also the flux permeability was increased from 6.44 for bare NF membrane to 20.11 $\mathrm{kg} / \mathrm{m}^{2}$.h for the membrane embedded with M-CMK-3. A higher rejection data for different dyes under different $\mathrm{pH}$ conditions (up to $90 \%$ ) was reported for the synthesized membrane embedded with M-CMK3. After all, from the obtained data, M-CMK-3 with higher negative surface charge presented a higher performance to remove salts and dyes. This research was aimed to develop cost-effective NF membranes with high antifouling properties and super high filtration capacity for removing dyes and salts from wastewaters.

\section{Introduction}

With increasing requirements for textile goods, the amount of textile wastewater increased rapidly in recent century [1,2]. As the most of dyes applied in textile industry are poisonous for the environment, this type of wastewater should be treated in terms of removing non-biodegradable dyes [3]. It should be noted that, textile wastewater containing considerable concentration of salts like $\mathrm{NaCl}$ and $\mathrm{Na}_{2} \mathrm{SO}_{4}$ besides toxic dyes caused further difficulties in treatment processes [4, 5]. In this mean, different treatment methods have been employed to remove non-biodegradable dyes from textile wastewater $[6,7]$ e.g. coagulation [8], oxidation [9], adsorption [10, 11], and membrane based technology. Among the mention methods, membrane technology is recognized as a cost-effective technology to attain sustainable dye recovery $[12,13]$.

Nanofiltration (NF) is a proper membrane type for salt rejection and dye removal as a result of high efficient and low energy consumption of NF technology rather than osmosis process [14]. Recently, many studies were focused on dye and salt removal from textile wastewater via NF process. As reported in the literature, polyether sulfone-base NF membranes represent an acceptable performance for rejecting most divalent salts (e.g. $\mathrm{Na}_{2} \mathrm{SO}_{4}$ ), however, low salt retention efficiency was observed for monovalent salts (e.g. $\mathrm{NaCl}$ ) [15]. More recently, many researches have been done to modify polyether sulfone-base NF membranes in order to enhance dye and salt removal from textile wastewater comprising the uses nanofillers in the matrix of polyether sulfone-base NF membranes like sulfonated grapheme oxide [16], $\mathrm{Fe}_{3} \mathrm{O}_{4} @ \mathrm{SiO}_{2}-\mathrm{NH}_{2}$ nanocomposite [17], magnetic grapheme oxide/metformin hybrid [18], cellulose nanocrystals [19] and etc. 
As a fact, both size exclusion and Donnan effect enhanced the dye and salts removal efficiencies for modified NF membranes compared to commercial polyether sulfone-base NF membranes. On the other hand, expensive materials applied more often to modify NF membranes which is a weak point to develop them to industry. Consequently, a simple and cost- effective strategy to generate high efficiency NF membranes is required to recover water from textile wastewater [20-25].

In this research, mesoporous carbon CMK-3 and modified CMK-3 with H-acid (M-CMK-3) were applied as additives in this research. The CMK-3 and M-CMK-3 were chosen as the required materials for the synthesis of nanoparticles are not expensive which makes them cost-effective additives along with the existent hydrophilic groups in their structure like $-\mathrm{OH},-\mathrm{NH}_{2}$ and $-\mathrm{SO}_{3}$. Also, $\mathrm{CMK}-3$ and $\mathrm{M}-\mathrm{CMK}-3$ provide high effective surface and high density of the hydrophilic functional groups. Therefore, a series of CMK-3 and modified M-CMK-3 NF membranes were synthesized and applied to remove four dyes including Direct red-16, Reactive blue 19, Rhodamine $b$ and Methylene blue and four different salts $\left(\mathrm{NaCl}, \mathrm{Na}_{2} \mathrm{SO}_{4}\right.$, $\left.\mathrm{NaNO}_{3}, \mathrm{CaCl}_{2}\right)$. Also, the effect of nanoparticle loading $(0.1,0.3,0.7$ and $1 \mathrm{wt} \%)$ on the morphology, membrane characteristics and performance and relative properties was assessed.

\section{Materials And Methods \\ 2.1. Materials}

Polyethersulfone (PES) $\left(\mathrm{MW}=58000 \mathrm{~g} \cdot \mathrm{mol}^{-1}\right)$ was chosen as the main polymer and dimethylacetamide (DMAc) (BASF Germany) was selected as solvent and Polyvinylpyrrolidone (PVP) (MW = $25000 \mathrm{~g} \mathrm{~mol}^{-1}$ ) was used as membrane pore maker. Also, tetraethylorthosilicate (TEOS, Merck); poly (ethylene glycol)block-poly (propylene glycol)-blockpoly (ethylene glycol) (P123, Aldrich), were used as a silica source and a structure-directing agent, respectively. 3-(choloropropyl)-trimethoxysilane (CPTMS, Merck), 1-amino-8naphthol-3,6-disulfonic acid monosodium salt (H-acid or ANDS, Merck), concentrated hydrochloric acid (Merck), and ethanol (Merck) also were supplied. The different dyes and salts utilized in this research as purchased from Merck and Sigma-Aldrich.

\subsection{Synthesis of CMK-3 and modified CMK-3}

High order silica template was applied to synthesize mesoporous carbon (CMK-3) as reported by Ryoo [26]. Ordered mesoporous silica Santa Barbara Amorphous-15 (SBA-15) was synthesized according Y. Zhao et al. [27]. $9.1 \mathrm{~g}$ of P123 (poly (ethylene glycol)-block-poly-(propylene glycol)-block-poly (ethylene glycol)) was dissolved in $288 \mathrm{~mL}$ of $\mathrm{HCl}(2 \mathrm{M})$ and temperature of the solution was kept $\mathrm{t}$ at $50^{\circ} \mathrm{C}$. After that, $22.2 \mathrm{~mL}$ of TEOS (tetraethylorthosilicate) were added to the solution and stirred for $20 \mathrm{~min}$ and then the obtained solution was kept without stirring for $24 \mathrm{~h}$. Then, it was heated at $80^{\circ} \mathrm{C}$ for $24 \mathrm{~h}$. Finally, to eliminate the template and achieve SBA- 15 the sample was calcined at $550^{\circ} \mathrm{C}$ over $5 \mathrm{~h}$ [26].

Figure 1. illustrates the overall synthesis routes and schematic representation of pore arrangements of CMK-3 illustrated. To synthesis CMK-3, $1 \mathrm{~g}$ of SBA-15 and $1.25 \mathrm{~g}$ of sucrose were first dissolved in $6 \mathrm{~g}$ of 
distillated $\mathrm{H}_{2} \mathrm{O}$ and $0.18 \mathrm{~g}$ of $\mathrm{H}_{2} \mathrm{SO}_{4}(98 \%)$ was added to the solution drop wisely. In the next step, the mixture was stirring for $1 \mathrm{~h}$, dried at $100^{\circ} \mathrm{C}$ for $6 \mathrm{~h}$ and then at $160^{\circ} \mathrm{C}$ for another $6 \mathrm{~h}$. The obtained sample was saturated another time with a solution containing of $0.75 \mathrm{~g}$ of sucrose, $4 \mathrm{~g}$ of distillated water and $0.08 \mathrm{~g}$ of $\mathrm{H}_{2} \mathrm{SO}_{4}$, and heated for $6 \mathrm{~h}$ at $100^{\circ} \mathrm{C}$ and at $160^{\circ} \mathrm{C}$ for another $6 \mathrm{~h}$. The resulting sample was carbonized by heating at $150{ }^{\circ} \mathrm{C}$ for $1 \mathrm{~h}$ and consequently at $900{ }^{\circ} \mathrm{C}$ for $3 \mathrm{~h}$ under $5 \% \mathrm{H}_{2} / 95 \%$ Ar atmosphere. Afterward, the silica template was detached by etching in $1 \mathrm{M} \mathrm{HF}\left(50 \mathrm{vol} \% \mathrm{H}_{2} \mathrm{O} / 50 \mathrm{vol} \%\right.$ ethanol). As a final step, CMK-3 was attained by filtration, washed with $\mathrm{H}_{2} \mathrm{O}$ several times, and dried at 60 ${ }^{\circ} \mathrm{C}[28]$.

In the next step, CMK-3 was modified by choloropropyl moiety. The synthesized CMK-3 $(1 \mathrm{~g})$ and dry toluene $(50 \mathrm{ml})$ were mixed in a two-neck round-bottom flask and stirred under heating at $40^{\circ} \mathrm{C}$. Then, (3Chloropropyl) trimethoxysilane (CPTMS) $(1 \mathrm{ml}$, about $5 \mathrm{mmol}$ ) was added to the mixture and refluxed for $24 \mathrm{~h}$. Afterward, to remove unreacted CPTMS, the sediment was filtered and washed several times with fresh dry toluene and the sample was dried at $100^{\circ} \mathrm{C}$ overnight. As a final step, the H-acid-modified CMK-3 (M-CMK-3) was prepared based on the following procedure. The H-acid (1-Amino-8-hydroxy-3,6naphthalenedisulfonic acid monosodium salt) $(10 \mathrm{mmol})$ was dissolved in methanol and water $(3: 1, \mathrm{v} / \mathrm{v})$. Then, $\mathrm{CMK}-3-\mathrm{Cl}(5 \mathrm{~g})$ and triethylamine $(10 \mathrm{mmol})$ were added to the solution and the mixture was stirred under reflux condition for $24 \mathrm{~h}$. To eliminate unreacted $\mathrm{H}$-acid, the obtained solid was filtered and washed several times with deionized water and methanol, after that, the resulting solid was dried at $100^{\circ} \mathrm{C}$ overnight.

\subsection{Preparation of membranes}

In this work, for membrane fabrication, the casting solution compositions were designed based on Table. 1. To obtain homogeneous solutions, the mixtures were well mixed by using continuous stirring for almost $24 \mathrm{~h}$, and also, the solution were sonicated (DT 102H Bandelin ultrasonic (Germany)) for $30 \mathrm{~min}$ (degas mood) to enhance the homogeneity. The obtained uniform solutions, were casted in $150 \mu \mathrm{m}$ thickness by applying a casting knife and several glassy plates. The glassy plates were transferred into non-solvent bath (distilled water) at once without any evaporation. The formed polymeric membranes were moved into fresh distilled water to make sure that the phase inversion completely have been finished (24h). Subsequently, the prepared membranes were dried in room temperature between filter papers. (Whatman $1001-734$ Grade 1, size: $46 \mathrm{cmX100m)}$ [29, 30].

Table 1. Membranes casting solution composition. 


\begin{tabular}{ccccc}
\hline Membrane type & PES (wt.\%) & PVP (wt.\%) & N.Ps (wt.\%) & DMAc (wt.\%) \\
\hline M1 & 20.0 & 1.0 & 0.0 & 79.0 \\
M2 & 20.0 & 1.0 & $0.1^{\mathrm{a}}$ & 78.9 \\
\hline M3 & 20.0 & 1.0 & $0.3^{\mathrm{a}}$ & 78.7 \\
\hline M4 & 20.0 & 1.0 & $0.7^{\mathrm{a}}$ & 78.3 \\
\hline M5 & 20.0 & 1.0 & $1.0^{\mathrm{a}}$ & 78.0 \\
\hline M6 & 20.0 & 1.0 & $0.1^{\mathrm{b}}$ & 78.9 \\
\hline M7 & 20.0 & 1.0 & $0.3^{\mathrm{b}}$ & 78.7 \\
\hline M8 & 20.0 & 1.0 & $0.7^{\mathrm{b}}$ & 78.3 \\
\hline M9 & 20.0 & 1.0 & $1.0^{\mathrm{b}}$ & 78.0 \\
\hline a: CMK-3, b: M-CMK-3 & & & & \\
\hline
\end{tabular}

\subsection{Characterizations}

With the aim of characterizing the prepared membrane, scanning electron microscope (SEM) (SEM, Philips-XL30, The Netherland), Atomic force microscopy (AFM) (Nanosurf ${ }^{\circledR}$ Mobile S scanning probeoptical microscope, Switzerland), Water contact angle (WCA) (contact angle meter XCA-50), SEM (TESCAN MIRA3) and The Fourier transform infrared spectroscopy (FT-IR, Bruker alpha, German), X-ray scattering (XRD) patterns (Zeta-Sizer Nano ZS, ZEN3600, Malvern).

\subsection{Porosity and mean pore radius}

a gravimetric method was applied to determine membrane porosity ( () . A piece of a membrane $\left(2 \times 2 \mathrm{~cm}^{2}\right)$ was weighed and after that immersed in distilled water for $24 \mathrm{~h}$ and weighed again. The following equation has been used to calculate porosity:

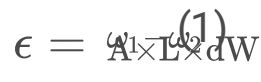

where, $\omega_{1}$ and $\omega_{2}$ are the weight of membrane after and before immersing in water, respectively. $A$ is the membrane efficacious area $\left(\mathrm{m}^{2}\right), L$ is the membrane thickness, and $d W$ is the density of water $(0.998$ $\left.\mathrm{g} / \mathrm{cm}^{3}\right)$ [31].

Besides, mean pore radius $\left(r_{m}\right)$ was calculated based on Guerout-Elford-Ferry Eq. (2):

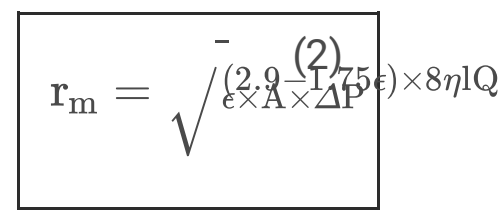


Where, $\eta$ is the water viscosity $\left(8.9 \times 10^{-4} \mathrm{~Pa} \mathrm{~s}\right), \mathrm{Q}$ is the volume of the permeate pure water per unit time $\left(\mathrm{m}^{3} / \mathrm{s}\right)$, and $\Delta \mathrm{P}$ is the operation pressure (4 bar).

\subsection{Separation performance tests}

To evaluate the performance of the prepared membranes, a dead-end setup with $150 \mathrm{ml}$ of volume and $12.54 \mathrm{~cm}^{2}$ of effective membrane area, made of stainless steel, was applied (Fig. 1). The setup was pressurized by inert gas $\left(\mathrm{N}_{2}\right)$ as transmembrane pressure (TMP). At the beginning of the filtration, the setup was permitted to reach steady state (15min), then the obtained data was recorded (4bar). By applying a digital balance according to gravimetric method s, the pure water flux (PWF) can be calculated following Eq. 3:

$$
J_{w .1}=\Delta \Delta t
$$

$\mathrm{J}_{\mathrm{W} .1}$ is membrane PWF $\left(\mathrm{kg} / \mathrm{m}^{2} . h\right), M$ is permeation weigh $(\mathrm{kg}), \mathrm{A}$ is membrane area $\left(\mathrm{m}^{2}\right)$, and $\Delta \mathrm{t}$ is filtration time $(h)$ [32].

To evaluate membrane antifouling behavior in contact with foulants, all the membranes were examined by 1000 ppm milk powder) GUIGOZ Growth 3 Formula Milk Powder from 1 year to 3 years (as simulated protein solution was recognized as good a foulant. In this way, 60 min distilled water, 90 min milk powder solution and again 60 min distilled water were filtered for each membrane (after milk powder test, the membranes were washed 10 min by distilled water). The membrane flux recovery ratio (FRR) was calculated according to equation 4 based on milk powder filtration data.

$$
F R R=(\text { 我㜛 } 100
$$

Where, Jw2 and Jw1 are the membrane PWF after and before milk powder solution test, respectively. Clearly, higher FRR values imply the membrane resistance ability against fouling and cake layer formation. To report accurate valuations, different types of resistance including total fouling ratio $\left(R_{\mathrm{t}}\right)$, reversible fouling ratio $\left(R_{\mathrm{r}}\right)$, and irreversible fouling ratio $\left(R_{\mathrm{ir}}\right)$ were calculated according to the following equations below: 


$$
\begin{gathered}
R_{t}(\%)=\left(1-\frac{j_{p}}{j_{w .1}}\right) \times 100 \\
R_{r}(\%)=\left(\frac{j_{w .2}-j_{p}}{j_{w .1}}\right) \times 100 \\
R_{i r}(\%)=\left(\frac{j_{w .1}-j_{w .2}}{j_{w .1}}\right) \times 100=R_{t}-R_{r}
\end{gathered}
$$

Where $\mathrm{j}_{\mathrm{p}}$ is the permeate flux for $24 \mathrm{~h}$. In this laboratory work, also the effect of two different types of feed (dye and salt) on membrane behavior, were investigated. The dye compounds are exhibited in Table 2. In $\mathrm{NF}$ test, the concentration of the solute before and after filtration was measured for different dyes at the maximum absorption wavelengths via a UV-Vis spectroscopy (Table 2) and a calibrated Electrical Conductivity Meter for inorganic salts, respectively. The actual concentration of solute was achieved through the standard calibration curves. The rejection rate of the CMK-3 membranes for salts or dyes was calculated by the following equation:

$$
R \%=\left(1-\xi_{F} \times 100\right.
$$

Where, $C_{P}$ and $C_{F}$ are the feed concentration in permeation and feed, respectively.

Table 2

The maximum absorption wavelengths of UV-Vis, molecular weights, hydrated radii, and charged types of the dyes used in this work [32,33].

\begin{tabular}{|lllll|}
\hline Dye molecules & Abbreviation & UV-vis $\boldsymbol{\lambda}_{\text {max }}, \mathrm{nm}$ & Molecular weight, $\mathbf{g} / \mathbf{m o l}$ & Charged type \\
\hline Direct red-16 & DR-16 & 526 & 637.55 & - at pH 6.5 \\
\hline Reactive blue 19 & RB-19 & 592 & 626.5 & - at pH 6.5 \\
\hline Rhodamine b & RhB & 560 & 479.02 & + at $\mathrm{pH} 6.5$ \\
\hline Methylene blue & MB & 586 & 319.85 & + at $\mathrm{pH} 6.5$ \\
\hline
\end{tabular}

\section{Results And Discussion}

\subsection{Characterization of Nano particles (CMK-3 and M-CMK- 3)}

To investigate the effect of modification with $\mathrm{H}$-acid on CMK-3, X-ray scattering (XRD) patterns of CMK-3 and M-CMK-3 were presented in Fig. 2. From the Fig. two diffractions peaks were observed for both CMK- 
3 and M-CMK-3, however, the resultant peaks of M-CMK-3 shifted so that the well - recognized peak appears in the range of $20-25$ of $2 \bigotimes$. Also, the intensity of peaks were reduced for M-CMK-3 resulting from decreasing in crystallinity, however, mesoporous framework has been maintained. These XRD patterns verified that the modification was satisfactory done on the mesoporous channels [33]. Besides, For the modified CMK-3, there is a shift in the peak position towards higher than 2 theta values, which indicates a decrease in the d-spacing (from $2.366 \AA$ for CMK-3 to $1.893 \AA$ for M-CMK-3) of the mesophase during the modification [34].

The FT-IR spectroscopy could be a proper analyze to prove the presence of CPTMS and $\mathrm{H}$-acid into the CMK-3 structure. Fig. 3a and b present the FT-IR spectra of CMK-3 and M-CMK-, respectively. The functional groups related to the observed bands have been specified. From Fig.3 the bands of $\mathrm{S}-\mathrm{H}, \mathrm{CH}_{2}$, $\mathrm{N}-\mathrm{H}, \mathrm{SO}, \mathrm{C}-\mathrm{O}, \mathrm{C}-\mathrm{N}$ for M-CMK-3 could be observed, however, they are missed for CMK-3. This observation is a significant verification to get a proper insertion of $\mathrm{H}$-acids into CMK-3. The band around $3500 \mathrm{~cm}^{-1}$ which is related to stretching $\mathrm{OH}$ could be observed for both spectra of CMK-3 and M-CMK-3, while the intensity of the peak is increased for M-CMK-3 rather than CMK-3. This observation besides the presence of the bands of $\mathrm{N}-\mathrm{H}, \mathrm{S}-\mathrm{O}$ for $\mathrm{M}-\mathrm{CMK}-3$ demonstrating the enhanced hydrophilicity property for $\mathrm{M}-\mathrm{CMK}-3$ compared to CMK-3.

Fig.4 $a$ and $b$ present the SEM images of CMK-3 and M-CMK-3. From Fig. $4 a$ and $b$, it could be seen that all images, indicating mesoporous structure of CMK-3, although, remarkable differences are observed in surface morphology between CMK-3 and M-CMK-3. It is evident that after modification, the CMK-3 surface becomes coarser and rougher. As shown in Fig.4, the surface of mesoporous carbon are involved spherical beads as a result of immobilizing the $\mathrm{H}$-acid function. It is notable that the structure of the mesoporous carbon remains intact after loading $\mathrm{H}$-acid on the surface $\mathrm{CMK}-3$ which is consistent with both XRD patterns (Fig. 2) [35]. Also, Fig.4c presented the size distribution of M-CMK-3, verifying that the size of nanoparticles was in the range of nanometers.

Also, the surface charge of CMK-3 and M-CMK-3 was evaluated by the zeta potential method (Fig.5). From Fig. 5 it could be observed that negative charge of M-CMK-3 is higher than CMK-3 (-28 versus -1.8) which is a sign of proper modification of CMK-3 by H-acid [36].

\subsection{Pure water flux (PWF) and water contact angle (WCA)}

In general, pore sizes, porosity and thickness are effective factors on the membrane filtration performance. The influence of the nanoparticle loading on porosity and mean pore radius $\left(r_{m}\right)$ are presented in Fig. 6a. As can be seen from the Fig. there is an inverse relationship between porosity and $\mathrm{rm}$. Besides, the membrane wettability is a significant specification of membranes which affects their water permeation. Figure $6 \mathrm{~b}$ displays the water contact angles and pure water flux for all resultant membranes (M1-M9). In overall, the lowest additive loading of both CMK-3 and M-CMK-3 presented the highest porosity and water flux. The highest pure water flux $\left(20.11 \mathrm{~kg} / \mathrm{m}^{2} . \mathrm{h}\right.$ at the pressure of 4 bar) was attained in M6 ( $0.1 \mathrm{wt} \%$ of M-CMK-3 membrane) which its porosity is reported as $88.23 \%$. This outcome 
implies a positive effect of low loading of M-CMK-3 on porosity and water flux of PES nanofiltration membrane.

From Fig. 6b, pure water flux was decreased from M2 to M5. As an explanation, at higher percentages of nanoparticles, there is a possibility of clogging and agglomeration of nanomaterials in membranes texture which caused a reduction in water flux. It should be noted that the presence of mesoporous nanomaterials (CMK-3) led to increasing the total porosity, however, at higher percentages of nanoparticles, clogging could be occurred which caused a reduction in pure water flux.

Also, it is observed from Fig. 6b that the membranes with embedded M-CMK-3 (M6-M9) have lower contact angles in comparative with those with embedded CMK-3 (M2-M5) which is attributed to the presence of hydrophilic functional groups in the surface of M-CMK-3 like hydroxyl $(-\mathrm{OH})$, amino $\left(-\mathrm{NH}_{2}\right)$ and sulfate $\left(-\mathrm{SO}_{3}\right)$ groups. The contact angles for M6-M9 are in the range of $46-56^{\circ}$.

It should be noted that the WCA was increased from M7 to M9. As a fact, the contact angle depends on the presence of nanomaterials on the membrane surface. At higher concentrations of M-CMK-3 (from M7 to M9) the probability of nanomaterial accumulation is high which increased the casting viscosity (Table 3). So, the presence of nanomaterials on the membrane surface will be decreased causing an increase in contact angle from M7-M9.

As the contact angle of $\mathrm{M} 6$ is about $50^{\circ}$ after $10 \mathrm{~s}$, and also its pure water flux was $20.11 \mathrm{~kg} / \mathrm{m}^{2} . \mathrm{h}$ (the highest pure water flux among others), it can be concluded that this dose of additive loading is more appropriate to use in the matrix of NF membrane to progress the rejection and water flux.

\subsection{Morphology Analysis}

To assess the cross-section morphology of the synthesized membranes, the SEM images were prepared (Fig. 7). The cross-section images showed asymmetric structure including a thin top layer and a sublayer with coarse pores. This event can be related to phase inversion rate over the membrane formation in distilled water due to the different casting solution viscosity (Table 3). In other words, by increasing the CMK-3 and M-CMK-3 to the membrane solution, hydrogen bonding is created between the functional groups of the nanomaterials $\left(-\mathrm{OH},-\mathrm{NH}_{2}\right.$ and $\left.-\mathrm{SO}_{3}\right)$ and polymer structure, which increases the viscosity of the casting solution, so this factor is effective in the phase inversion step for membrane formation and the migration of nanomaterials to the membrane surface. More hydrophilic nature of casting solution in modified membranes caused an increase in phase inversion rate [18]. Besides, high settlement between polymeric matrix and the CMK-3 and M-CMK-3 nanoparticles could be proved by the homogeneous distribution of additives. From Fig. 7 membranes with fewer CMK-3 and M-CMK-3 loading showed more loose pores than those with more additive loading (M2 and M6 against M5 and M9). This outcome may be related to using higher loading of the hydrophilic nanoparticles (CMK-3 and M-CMK-3), accelerating diffusion rate of water into the matrix of membrane over the phase inversion which is caused tinier pores. 


\begin{tabular}{|ll|}
\hline \multicolumn{2}{|l|}{ Table 3. Viscosity } \\
\hline Membrane & Viscosity, cP \\
\hline M1 & 223 \\
\hline M2 & 294 \\
\hline M5 & 396 \\
\hline M6 & 341 \\
\hline M9 & 633 \\
\hline
\end{tabular}

The EDX and EDX mapping were performed and the results are displayed for a series of membranes in Fig. 8. As can be seen from the Fig. the picks of Si and N disappeared for original PES membrane (M1), nevertheless, for all modified membranes the Si peak could be recognized (M2-M9). This observation indicates that the modified membranes were covered properly with CMK-3 complex. The Si content in membrane matrix increased as CMK-3 loading was increased (from M2 to M5 and M6 to M9). Besides, the $\mathrm{N}$ peak appears in M6-M9 as a result of adding M-CMK-3, comprising functional group of $\mathrm{NH}_{2}$. EDX mapping images demonstrate that $\mathrm{N}$ and $\mathrm{Si}$ elements were distributed appropriately in the membrane matrix.

The surface topography of the membranes was evaluated by AFM, so that the lighter and darker areas in the three-dimensional AFM images are representative peaks and valleys on the membrane surface (the difference between the highest and lowest points described as roughness). As a fact, the surface with high roughness acts as a trap to absorb foulants on the surface of membrane which led to membrane fouling and a flux reduction. The obtained results from the preliminary analysis of membrane surface roughness are presented in Fig. 9 and Table. 4. Random samples of the prepared membranes were chosen to surface evaluations. Based on Table. 4, M1 in compare with modified membranes showed the highest roughness $\left(S_{a}, 9.66 \mathrm{~nm}\right)$ with an average amounts of difference between the highest peak and the lowest valley $(\mathrm{Sz})$ of $65.71 \mathrm{~nm}$ and the root mean square of the $Z$ data $(\mathrm{Sq})$ of $12.10 \mathrm{~nm}$. As a result, $\mathrm{Sa}, \mathrm{Sz}$ and Sq data of modified membranes (M2-M9) verify that the surface of modified membranes becomes smoother. M6 indicated the least amounts of Sa $(1.07 \mathrm{~nm}), \mathrm{Sz}(2.30 \mathrm{~nm})$ and Sq $(1.36 \mathrm{~nm})$ indicating M-CMK-3 with minimum loading (0.1 wt\%) is an optimum membrane in agreement with SEM images, contact angle and pure water flux data. As a matter of fact, rough surface traps the foulants in the space between peaks and valleys, so, more smooth surface of the modified membranes reduced the cake-layer formation and also enhanced the membrane antifouling potential [37, 38]. 
Table 4

Membrane surface roughness of bare and modified nanofiltration PES membranes.

\begin{tabular}{|llll|}
\hline Membrane & $S_{\mathbf{a}}(\mathrm{nm})$ & $\mathrm{S}_{\mathrm{q}}(\mathrm{nm})$ & $\mathrm{S}_{\mathbf{z}}(\mathrm{nm})$ \\
\hline $\mathrm{M} 1$ & 9.66 & 12.10 & 65.71 \\
\hline M2 & 1.54 & 1.62 & 2.75 \\
\hline M3 & 6.13 & 6.20 & 2.61 \\
\hline M4 & 1.42 & 1.96 & 31.99 \\
\hline M5 & 1.08 & 1.47 & 37.88 \\
\hline M6 & 1.07 & 1.36 & 2.3 \\
\hline M7 & 1.36 & 1.82 & 34.83 \\
\hline M9 & 1.34 & 1.79 & 23.33 \\
\hline
\end{tabular}

\subsection{Antifouling behavior}

In this part, the membranes fouling characteristic of the resultant membranes was investigated by a three step analysis including first and third steps of distilled water filtration and second step of protein filtration (1000 ppm milk powder solution). The experimental data are shown in Fig. 10. Suffice it to say that, PWF of the applied membranes before and after milk powder filtration (first and third step of distilled water filtration) almost showed no remarkable reduction for modified membrane comparing to the bare membrane. According to the Fig. 10, M1 showed the least PWF in the first step. Besides, the mentioned membrane (M1) faced with fouling phenomenon after filtering milk powder solution and PFW reduced in third step, indicating low antifouling property of bare NF membrane. The modifications applied showed an enhancement on the membrane permeation flux relative to the naked membrane (M1). Among the modified membranes, M6 represented the highest PWF in the first and third steps and there are no any signs of fouling phenomenon milk powder solution filtration. Initial PWF for M6 was about $20.11 \mathrm{~kg} / \mathrm{m}^{2} . \mathrm{h}$ while it was $6.4 \mathrm{~kg} / \mathrm{m}^{2}$.h for the bare membrane. The observed tending for M6 was compatible with the results obtained in membrane characteristics reported earlier including hydrophobicity and morphology of membranes.

Following the results of milk powder filtration, the flux recovery ratio (FRR) (Fig. 11a), reversible resistance $\left(R_{r}\right)$ and irreversible resistance $\left(R_{\text {ir }}\right)$ were calculated for accurate evaluation of the membrane separation process (Fig. 11b). Based on the data in Fig. 11, bare NF membrane (M1) shows the lowest FRR (67.84\%) and $R_{r}(4.37 \%)$ and the highest value of $R_{i r}(32.16 \%)$, while a series of modified membranes demonstrate 
an acceptable performance. The modified membranes with M-CMK-3 present better performance in terms of FRR, $R r$ and especially Rir. M6 showed the maximum FRR (99.87\%), and $R_{r}(79.21 \%)$ and minimum $R_{i r}$ $(0.13 \%)$ in compare with other modified membranes. In overall, high membrane surface hydrophilicity, membrane surface smoothness, additive dispersion uniformity in membrane matrix, thin membrane toplayer and thick sub-layer, are the results of membrane modification with the negatively charged M-CMK-3 in optimal percentage $(0.1 \mathrm{wt} \%)$. It should be noted that an inhibiting effect against foulant formation on the membrane surface was supplied by hydrogen bonding on the membrane surface as a subsequence of the presence of hydrophilic functional groups $\left(-\mathrm{SO}_{3},-\mathrm{NH}\right.$ and $\left.-\mathrm{OH}\right)$. The Low Rir value obtained for the M6 $(0.13 \%)$ is a good approval on its capability for dye/salt removal. [17].

\subsection{Salt rejection}

It should be mentioned that, with considering FRR, $R_{r}$ and $R_{i r}$ obtained for modified membranes, two of them were selected as the optimum membranes to test salt removal efficiencies comprising M2 (for a series membrane with embedded CMK-3) and M6 (for a series membrane with embedded M-CMK-3). The salt rejection performances of $\mathrm{M} 1, \mathrm{M} 2$ and $\mathrm{M} 6$ were evaluated by the filtration of $\mathrm{Na}_{2} \mathrm{SO}_{4}, \mathrm{NaNO}_{3}, \mathrm{NaCl}$ and $\mathrm{CaCl}_{2}$ solutions with concentration of $5 \mathrm{mM}$. As a notice, salt rejection test was performed for both monovalent ions $\left(\mathrm{Na}^{+}, \mathrm{Cl}^{-}\right.$and $\left.\mathrm{NO}_{3}{ }^{-}\right)$and divalent ions $\left(\mathrm{SO}_{4}{ }^{2-}\right.$ and $\left.\mathrm{Ca}^{2+}\right)$ to achieve a more comprehensive assessment. As shown in Fig. 12b, the presence of CMK-3 and M-CMK-3 caused an increase in water flux of $\mathrm{M} 2$ and $M 6$ relative to $M 1$ for all kinds of salt solutions tested. Between two chosen modified membranes, M6 possessed the highest water flux of $23.71 \mathrm{~kg} / \mathrm{m}^{2}$.h against M1 with water flux of $6.39 \mathrm{~kg} / \mathrm{m}^{2}$.h which these results are consistent with membrane permeability discussed earlier. Also, from Fig. 12a, M6 presents higher efficiency for removal all kinds of salts compared with the data reported for M1 and M2. This outcome could be explained by the zeta potential of CMK-3 and MCMK-3 reported in Fig. 5. As a fact, the surface of M-CMK-3 showed remarkable negative charged respect to CMK-3 (-28 mV versus $-1.8 \mathrm{mV}$ ) which caused an effective negatively charged surface for M6 membrane, so, $\mathrm{M} 6$ is more capable for anion repulsion. The salt rejection rate pursued the order of $\mathrm{Na}_{2} \mathrm{SO}_{4}>\mathrm{CaCl}_{2}>\mathrm{NaCl}>\mathrm{NaNO}_{3}$. This phenomenon can be deduced by electrostatic interaction and size exclusion. The divalent ions of $\mathrm{Ca}^{2+}(4.12 \AA)$ and $\mathrm{SO}_{4}{ }^{2-}(3.79 \AA)$ possess large hydration radius compared with monovalent ions $\mathrm{Na}^{+}(3.58 \AA)$ and $\mathrm{Cl}^{-}(3.32 \AA)$, which caused a greater resistance to pass through the NF membrane for divalent ions [39-41]. The rejection rate of $\mathrm{Na}_{2} \mathrm{SO}_{4}$ was achieved higher than $\mathrm{CaCl}_{2}$ as the surface charge of the membrane is negative (Fig. 5 and Fig. $6 \mathrm{~b}$ ), the repulsive effect causes higher removal percentage of $\mathrm{SO}_{4}{ }^{2-}$ ion rather than other salts (Fig. 12a). Also, the hydration radius of $\mathrm{Cl}^{-}(3.32 \AA)$ is lower than $\mathrm{SO}_{4}{ }^{2-}(3.79 \AA)$, causing an increase in the rejection rate for $\mathrm{SO}_{4}{ }^{2-}$. Another reason that can be mentioned is the presence of more negative hydration energy in $\mathrm{Ca}^{2+}(-1505$ $\mathrm{kJ} / \mathrm{mol})$ than $\mathrm{SO}_{4}{ }^{2-}(-1080 \mathrm{~kJ} / \mathrm{mol})$. The more negative the hydration energy, the more scattering and solubility of the elements which makes separation harder. Therefore, the removal percentage of $\mathrm{Na}_{2} \mathrm{SO}_{4}$ was achieved higher than $\mathrm{CaCl}_{2}$ [37-39]. The lowest rejection percentage was reported for $\mathrm{NaNO}_{3}$ which 
could be related to the hydrated form of $\mathrm{NO}_{3}{ }^{-}$ion in aqueous solution, causing an enhanced dispersion in water and harder separation.

\subsection{Dye removal}

Figure 13 displays the dye rejection performance of the applied membranes for four dye molecules with initial concentration of 30 ppm including direct red-16 (DR-16), reactive blue-19 (RB-19), rhodamine B $(\mathrm{RhB})$ and methylene blue (MB). It should be noted that these dyes are classified into two charge types including positive charged dye molecules: RhB and MB, and negative charged dye molecules: DR-16 and RB-19 (Table 2). It is obvious that the lowest dye rejection is related to M1 (bare NF membrane) due to the greater osmotic pressure resulted from pores blocked with dye molecules. As a fact, the modified membranes presented better performances as a result of their smaller size of pores and more negative surface charge. Among all dyes, the rejection data of DR-16 and RB-19 are higher than the MB and RhB for all membranes tested. This outcome could be elucidated by size sieving and electrostatic repulsion. The molecular size of DR-16 (637.55 g/mol) and RB-19 (626.53 g/mol) are larger than MB (319.85 $\mathrm{g} / \mathrm{mol})$, and RhB (479.02 $\mathrm{g} / \mathrm{mol})$ which led to high-penetration resistance and higher rejection percentages for DR-16 and RB-19. Besides, according to Donan effect theory, the rejection rate of negatively charged dyes comprising DR-16 and RB-19 is higher than positively charged ones [39,42-44].

In overall, NF membranes embedded with M-CMK-3 (M6-M9) showed higher rejection percentages (up to $97 \%$ of dye rejections for all dyes) in compare to NF membranes embedded with CMK-3 (M2-M5). As an explanation, according to on zeta potential data (Fig. 6), M-CMK-3 resulted higher negatively charged surface relative to CMK-3 caused an improved electrostatic repulsion for negatively charged dyes (DR-16 and RB-19). Also, M-CMK-3 membranes rejected positively charged dyes satisfactorily along with negatively charged ones because of sieving effect. As a conclusion, the membranes embedded with $M$ CMK-3 are developed in terms of rejection due to both physical size and electrostatic effect relative to the membranes embedded with CMK-3.

Also, three different feed pHs (acidic, nature, basic) were examined for comparing the behavior of the bare and optimal modified membranes (M2 and M6). Figure 14a-d showed the performances of M1, M2 and M6 to reject DR-16, RB-19, RhB and MB, respectively. From the Figs. M6 presented higher rejection percentages for all dyes used under different PHs.

The membranes (M1, M2 and M6) exhibited the least removal rates for dye solutes under acidic conditions. From the experimental results, the highest rejection is related to the basic $\mathrm{pH}$. In acidic feed, higher concentrations of $\mathrm{H}^{+}$cause some changes on the dye particles nature so that their surface charges shifted to positive charges. As a fact, the surface charge of M-CMK-3 based membrane (M6) is neutral in acidic conditions as $\mathrm{H}$-acid reacted with $\mathrm{CMK}-3$ by $\mathrm{NH}_{2}$ group, (see $\mathrm{C}-\mathrm{N}$ bands in Fig. 3b). Subsequently, the major mechanism for dye removal was size sieving under acidic condition, so the dyes with higher molecular size (DR-16 and RB-19) showed higher rejection data [45, 46]. 
In alkali $\mathrm{pH}$, the $-\mathrm{SO}_{3}$ and $-\mathrm{OH}$ functional groups on the surface of $\mathrm{M}-\mathrm{CMK}-3$ change into negative form. As can be seen from the Figs., there is a contrast between membrane rejection in negative (DR-16 and RB19) and positive (RhB and $\mathrm{MB}$ ) dye compounds resulted from membrane filtration ability according to electrostatic repulsion (different nature of dyes) and Gibbs-Donnan effect (different size of dyes) [46, 47].

Table 5 compares the performance of some modified membranes embedded with different nanofillers for removing dye and salt. In overall, M-CMK-3 presented better performance in terms of removing salts and dyes rather than $\mathrm{TiO}_{2}, \mathrm{TiO}_{2}-\mathrm{Al}_{2} \mathrm{O}_{3}, \mathrm{UiO}-66-\mathrm{NH}_{2}, \mathrm{GO}$ as fillers to modify $\mathrm{NF}$ membranes. This comparison verified high density of hydrophilic functional groups on the surface of M-CMK-3 in this research which make the NF membrane more efficient to remove dyes and salts. 
Table 5

Performance comparison of the modified membrane with reported membranes.

\begin{tabular}{|c|c|c|c|c|c|c|c|}
\hline Polymer & $\begin{array}{l}\text { Membrane } \\
\text { type }\end{array}$ & Nanofiller & salt & Dye & $\begin{array}{l}\text { Salt } \\
\text { rejection, } \\
\%\end{array}$ & $\begin{array}{l}\text { Dye } \\
\text { rejection, } \\
\text { \% }\end{array}$ & Ref. \\
\hline \multirow[t]{5}{*}{ PSF } & \multirow[t]{5}{*}{ NF } & \multirow[t]{5}{*}{ GO } & $\mathrm{MgSO}_{4}$ & \multirow[t]{5}{*}{-} & 90 & - & \multirow[t]{5}{*}{ [48] } \\
\hline & & & $\mathrm{NaCl}$ & & 31 & & \\
\hline & & & $\mathrm{KCl}$ & & 32 & & \\
\hline & & & $\mathrm{CaCl}_{2}$ & & 53 & & \\
\hline & & & $\mathrm{MgCl}_{2}$ & & 64 & & \\
\hline \multirow[t]{4}{*}{ PS } & \multirow[t]{4}{*}{ NF } & \multirow{4}{*}{$\begin{array}{l}\text { Cellulose } \\
\text { nanocrystals }\end{array}$} & $\mathrm{MgSO}_{4}$ & \multirow[t]{4}{*}{-} & 92 & - & \multirow[t]{4}{*}{ [40] } \\
\hline & & & $\mathrm{NaCl}$ & & 32 & & \\
\hline & & & $\mathrm{CaCl}_{2}$ & & 50 & & \\
\hline & & & $\mathrm{MgCl}_{2}$ & & 45 & & \\
\hline \multirow{5}{*}{$\begin{array}{l}\text { Chitosan } \\
\text { PEG-400 }\end{array}$} & \multirow[t]{5}{*}{ NF } & \multirow[t]{5}{*}{ CS } & $\mathrm{Na}_{2} \mathrm{SO}_{4}$ & \multirow{3}{*}{$\begin{array}{l}\text { Methyl } \\
\text { Orange } \\
\text { Brilliant } \\
\text { blue }\end{array}$} & 75 & 99 & \multirow[t]{5}{*}{ [39] } \\
\hline & & & $\mathrm{MgSO}_{4}$ & & 87 & 99 & \\
\hline & & & $\mathrm{NaCl}$ & & 32 & 99 & \\
\hline & & & \multirow[t]{2}{*}{$\mathrm{CaCl}_{2}$} & $\begin{array}{l}\text { Methyl } \\
\text { Viologen }\end{array}$ & 93 & 99 & \\
\hline & & & & $\begin{array}{l}\text { Methylene } \\
\text { blue }\end{array}$ & & & \\
\hline \multirow[t]{4}{*}{ CaAlg } & \multirow[t]{4}{*}{ NF } & \multirow[t]{4}{*}{$\mathrm{TiO}_{2}$} & $\mathrm{Na}_{2} \mathrm{SO}_{4}$ & Brilliant & 15 & 98 & \multirow[t]{4}{*}{ [49] } \\
\hline & & & $\mathrm{MgSO}_{4}$ & Direct & 16 & 96 & \\
\hline & & & $\mathrm{NaCl}$ & black-38 & 9 & 95 & \\
\hline & & & $\mathrm{MgCl}_{2}$ & Congo red & 12 & & \\
\hline \multirow{2}{*}{$\begin{array}{l}\text { Ceramic } \\
\text { membrane }\end{array}$} & \multirow[t]{2}{*}{ NF } & \multirow{2}{*}{$\begin{array}{l}\mathrm{TiO}_{2} \text { and } \mathrm{a}- \\
\mathrm{Al}_{2} \mathrm{O}_{3}\end{array}$} & $\mathrm{Na}_{2} \mathrm{SO}_{4}$ & \multirow{2}{*}{$\begin{array}{l}\text { Eriochrome } \\
\text { black T }\end{array}$} & 40 & 99 & \multirow[t]{2}{*}{ [50] } \\
\hline & & & $\mathrm{NaCl}$ & & 20 & & \\
\hline
\end{tabular}




\begin{tabular}{|c|c|c|c|c|c|c|c|}
\hline Polymer & $\begin{array}{l}\text { Membrane } \\
\text { type }\end{array}$ & Nanofiller & salt & Dye & $\begin{array}{l}\text { Salt } \\
\text { rejection, } \\
\%\end{array}$ & $\begin{array}{l}\text { Dye } \\
\text { rejection, } \\
\%\end{array}$ & Ref. \\
\hline \multirow[t]{4}{*}{ PES } & \multirow[t]{4}{*}{ NF $18 \%$} & \multirow[t]{4}{*}{ UiO-66- $\mathrm{NH}_{2}$} & \multirow[t]{4}{*}{-} & Congo red & - & 97 & \multirow[t]{4}{*}{ [51] } \\
\hline & & & & Orange $\otimes$ & & 83 & \\
\hline & & & & \multicolumn{2}{|l|}{$\begin{array}{l}\text { Crystal } \\
\text { violet }\end{array}$} & 67 & \\
\hline & & & & $\begin{array}{l}\text { Methylene } \\
\text { blue }\end{array}$ & & 62 & \\
\hline \multirow[t]{5}{*}{ PES } & \multirow[t]{5}{*}{ NF $20 \%$} & \multirow[t]{5}{*}{$\begin{array}{l}\mathrm{H} \text {-acid-CMK- } \\
3\end{array}$} & $\mathrm{Na}_{2} \mathrm{SO}_{4}$ & $\begin{array}{l}\text { Direct red- } \\
16\end{array}$ & 95 & 99.8 & \multirow[t]{5}{*}{$\begin{array}{l}\text { This } \\
\text { study }\end{array}$} \\
\hline & & & $\mathrm{NaNO}_{3}$ & \multirow{2}{*}{$\begin{array}{l}\text { Real } \\
\text { liquorice }\end{array}$} & 33 & 99.6 & \\
\hline & & & $\mathrm{NaCl}$ & & 61 & 99.2 & \\
\hline & & & $\mathrm{CaCl}_{2}$ & $\begin{array}{l}\text { Rhodamine } \\
\text { B }\end{array}$ & 64 & 99.4 & \\
\hline & & & & $\begin{array}{l}\text { Methylene } \\
\text { blue }\end{array}$ & & & \\
\hline
\end{tabular}

\subsection{Long-term filtration}

To achieve the membrane performance over long-term filtration, the optimal membranes including M2 and $\mathrm{M} 6$ and the bare membrane (M1) were tested for dye removal with colored wastewater (a mix solution of four dyes with concentration of $50 \mathrm{ppm}$ ) over $1380 \mathrm{~min}$. The obtained results are presented in Fig. 15. As can be seen from the Fig., the modified membranes (M2 and M6) showed significantly higher flux in comparison with the bare membrane. Besides, the trend stability of the tested membranes is another evidence for improving membrane performance after modification. From the Fig. a prominent reduction in flux trend could be observed for the bare membrane (M1) as a result of fouling completely after three-cycle filtrations. This can be directly related to the PES hydrophobic nature (higher WCA, Fig. 6b), which tends to absorb foulants and creates a cake layer on the membrane surface. As explained before, the surface roughness can intensify this phenomenon. In contrast, M6 exhibited the most stable trend. A small reduction in the performance for $\mathrm{M} 2$ is related to higher irreversible fouling ratio compared to M6. As a known fact, long-term filtration can be directly affected by membrane fouling resistance.

\section{Conclusion}


Novel mesoporous membranes are facilely fabricated through phase inversion method. The effect of additive loading on the morphology, porosity, permeability, and separation performance of the membranes embedded with CMK-3 and M-CMK-3 were studied. Membranes with optimum additive loading $(0.1 \mathrm{wt} \%)$ for CMK-3 and M-CMK-3 showed the highest rejection of $83 \%$ and $95 \%$ for $\mathrm{Na}_{2} \mathrm{SO}_{4}$, while maintain a stable water flux about 16 and $23 \mathrm{~kg} / \mathrm{m}^{2}$.h, respectively. The salt rejection followed the order of $\mathrm{Na}_{2} \mathrm{SO}_{4}>\mathrm{CaCl}_{2}>\mathrm{NaCl}>\mathrm{NaNO}_{3}$. From the dyes separation results, the modified membranes revealed the superior rejection over $97 \%$ for negative and positive charged dyes. Also, the performance stability of the membranes was investigated by the use of different $\mathrm{pH}$ solution dyes. As a conclusion, the membrane embedded with M-CMK-3 represented higher negatively surface charged, hydrophilicity, antifouling characteristics and rejection rate of different salts and dyes under different $\mathrm{pH}$ conditions. This study illustrated that a newly developed hydrophilic NF membrane with superior potential for dye and salt removal could be attained by applying M-CMK-3 in polyethersulfone.

\section{Declarations}

\section{Declaration of interests}

The authors declare that they have no known competing financial interests or personal relationships that could have appeared to influence the work reported in this paper.

\section{References}

1. Robinson T, McMullan G, Marchant R, Nigam P (2001) Remediation of dyes in textile effluent: a critical review on current treatment technologies with a proposed alternative. Bioresour Technol 77:247-255

2. Holkar CR, Jadhav AJ, Pinjari DV, Mahamuni NM, Pandit AB (2016) A critical review on textile wastewater treatments: possible approaches. Journal of environmental management 182:351-366

3. Le TXH, Van Nguyen T, Yacouba ZA, Zoungrana L, Avril F, Petit E, Mendret J, Bonniol V, Bechelany M, Lacour S, Toxicity removal assessments related to degradation pathways of azo dyes: toward an optimization of electro-Fenton treatment, Chemosphere, 161 (2016) 308-318

4. Mansour HB, Mosrati R, Ghedira K, Chekir-Ghedira L (2011) Decolorization of textile wastewater by Pseudomonas putida: toxicity assessment. Environ Eng Sci 28:489-495

5. Koparal AS, Yavuz Y, Gürel C, Öğütveren ÜB (2007) Electrochemical degradation and toxicity reduction of $\mathrm{Cl}$ Basic Red 29 solution and textile wastewater by using diamond anode. $\mathrm{J}$ Hazard Mater 145:100-108

6. Tufa RA, Curcio E, Brauns E, van Baak W, Fontananova E, Di Profio G (2015) Membrane distillation and reverse electrodialysis for near-zero liquid discharge and low energy seawater desalination. $J$ Membr Sci 496:325-333 
7. Werber JR, Deshmukh A, Elimelech M (2016) The critical need for increased selectivity, not increased water permeability, for desalination membranes. Environmental Science Technology Letters 3:112120

8. Han G, Liang C-Z, Chung T-S, Weber M, Staudt C, Maletzko C (2016) Combination of forward osmosis (FO) process with coagulation/flocculation (CF) for potential treatment of textile wastewater. Water Res 91:361-370

9. Asghar A, Raman AAA, Daud WMAW (2015) Advanced oxidation processes for in-situ production of hydrogen peroxide/hydroxyl radical for textile wastewater treatment: a review. Journal of cleaner production 87:826-838

10. Oveisi M, Asli MA, Mahmoodi NM (2018) MIL-Ti metal-organic frameworks (MOFs) nanomaterials as superior adsorbents: Synthesis and ultrasound-aided dye adsorption from multicomponent wastewater systems. J Hazard Mater 347:123-140

11. Wang S, Guan Y, Wang L, Zhao W, He H, Xiao J, Yang S, Sun C (2015) Fabrication of a novel bifunctional material of $\mathrm{BiOl} / \mathrm{Ag} 3 \mathrm{VO} 4$ with high adsorption-photocatalysis for efficient treatment of dye wastewater. Appl Catal B 168:448-457

12. Oulad F, Zinadini S, Zinatizadeh AA, Derakhshan AA (2020) Fabrication and characterization of a novel tannic acid coated boehmite/PES high performance antifouling NF membrane and application for licorice dye removal. Chem Eng J 397:125105

13. Han G, Chung T-S, Weber M, Maletzko C (2018) Low-pressure nanofiltration hollow fiber membranes for effective fractionation of dyes and inorganic salts in textile wastewater. Environ Sci Technol 52:3676-3684

14. Han G, Feng Y, Chung T-S, Weber M, Maletzko C (2017) Phase inversion directly induced tight ultrafiltration (UF) hollow fiber membranes for effective removal of textile dyes. Environ Sci Technol 51:14254-14261

15. Cheng XQ, Wang ZX, Jiang X, Li T, Lau CH, Guo Z, Ma J, Shao L (2018) Towards sustainable ultrafast molecular-separation membranes: from conventional polymers to emerging materials. Prog Mater Sci 92:258-283

16. Kang Y, Obaid M, Jang J, Kim IS (2019) Sulfonated graphene oxide incorporated thin film nanocomposite nanofiltration membrane to enhance permeation and antifouling properties. Desalination 470:114125

17. Kamari S, Shahbazi A (2020) Biocompatible Fe304@ SiO2-NH2 nanocomposite as a green nanofiller embedded in PES-nanofiltration membrane matrix for salts, heavy metal ion and dye removal: Long-term operation and reusability tests. Chemosphere 243:125282

18. Abdi G, Alizadeh A, Zinadini S, Moradi G (2018) Removal of dye and heavy metal ion using a novel synthetic polyethersulfone nanofiltration membrane modified by magnetic graphene oxide/metformin hybrid. J Membr Sci 552:326-335

19. Daraei P, Ghaemi N, Ghari HS (2017) An ultra-antifouling polyethersulfone membrane embedded with cellulose nanocrystals for improved dye and salt removal from water. Cellulose 24:915-929 
20. Lin J, Ye W, Baltaru M-C, Tang YP, Bernstein NJ, Gao P, Balta S, Vlad M, Volodin A, Sotto A (2016) Tight ultrafiltration membranes for enhanced separation of dyes and $\mathrm{Na2SO} 4$ during textile wastewater treatment. J Membr Sci 514:217-228

21. Li M, Yao Y, Zhang W, Zheng J, Zhang X, Wang L (2017) Fractionation and concentration of highsalinity textile wastewater using an ultra-permeable sulfonated thin-film composite. Environmental Science Technology 51:9252-9260

22. Zhu J, Tian M, Hou J, Wang J, Lin J, Zhang Y, Liu J (2016) B. Van der Bruggen, Surface zwitterionic functionalized graphene oxide for a novel loose nanofiltration membrane. Journal of Materials Chemistry A 4:1980-1990

23. Zhu J, Tian M, Zhang Y, Zhang H, Liu J (2015) Fabrication of a novel “loose” nanofiltration membrane by facile blending with Chitosan-Montmorillonite nanosheets for dyes purification. Chem Eng J 265:184-193

24. Ye W, Liu H, Lin F, Lin J, Zhao S, Yang S, Hou J, Zhou S, Van der Bruggen B (2019) High-flux nanofiltration membranes tailored by bio-inspired co-deposition of hydrophilic gC $3 \mathrm{~N} 4$ nanosheets for enhanced selectivity towards organics and salts, 6. Nano, Environmental Science, pp 2958-2967

25. Ye W, Lin J, Borrego R, Chen D, Sotto A, Luis P, Liu M, Zhao S, Tang CY, Van der Bruggen B (2018) Advanced desalination of dye/ $\mathrm{NaCl}$ mixtures by a loose nanofiltration membrane for digital ink-jet printing. Sep Purif Technol 197:27-35

26. Jun S, Joo SH, Ryoo R, Kruk M, Jaroniec M, Liu Z, Ohsuna T, Terasaki O (2000) Synthesis of new, nanoporous carbon with hexagonally ordered mesostructure. J Am Chem Soc 122:10712-10713

27. Zhao D, Feng J, Huo Q, Melosh N, Fredrickson G, Chmelka B, GD Stucky Science https://doi. org/10.1126/science. 279.5350. 548 279, 548 (1998), Scholar Crossref G, Zhao D, Huo Q, Feng J, Chmelka BF, Stucky GD, J. Am. Chem. Soc. https://doi. org/10.1021/ja974025i, 120 (1998) 6024

28. Kalbasi RJ, Parishani P, Mazaheri O (2018) Encapsulation of Nickel Nanoparticles and Homopoly (Vinylsulfonic Acid) in Mesoporous Carbon CMK-3 as an Acid-Metal Bifunctional Catalyst for Tandem Reductive Amination. J Cluster Sci 29:561-575

29. Zinadini S, Zinatizadeh AA, Rahimi M, Vatanpour V, Zangeneh H (2014) Preparation of a novel antifouling mixed matrix PES membrane by embedding graphene oxide nanoplates. J Membr Sci 453:292-301

30. Gholami F, Zinadini S, Zinatizadeh A, Abbasi AJS, Technology P, TMU-5 metal-organic frameworks (MOFs) as a novel nanofiller for flux increment and fouling mitigation in PES ultrafiltration membrane, 194 (2018) 272-280

31. Mohammadnezhad F, Feyzi M, Zinadini S (2019) A novel Ce-MOF/PES mixed matrix membrane; synthesis, characterization and antifouling evaluation. Journal of industrial engineering chemistry 71:99-111

32. Zinadini S, Gholami F (2016) Preparation and characterization of high flux PES nanofiltration membrane using hydrophilic nanoparticles by phase inversion method for application in advanced wastewater treatment. Journal of Applied Research in Water Wastewater 3:232-235 
33. Zarabadi-Poor P, Badiei A, Yousefi AA, Barroso-Flores J (2013) Selective optical sensing of $\mathrm{Hg}$ (II) in aqueous media by H-Acid/SBA-15: A combined experimental and theoretical study. J Phys Chem C 117:9281-9289

34. Roy S, Banerjee B, Salam N, Bhaumik A, Islam SM, Mesoporous titania-iron (III) Oxide with nanoscale porosity and high catalytic activity for the synthesis of $\beta$-amino alcohols and benzimidazole derivatives, ChemCatChem, 7 (2015) 2689-2697

35. Dibandjo P, Chassagneux F, Bois L, Sigala C, Miele P (2005) Comparison between SBA-15 silica and CMK-3 carbon nanocasting for mesoporous boron nitride synthesis. J Mater Chem 15:1917-1923

36. Yang Y, Wang J, Qian X, Shan Y, Zhang H (2018) Aminopropyl-functionalized mesoporous carbon (APTMS-CMK-3) as effective phosphate adsorbent. Appl Surf Sci 427:206-214

37. Oulad F, Zinadini S, Zinatizadeh AA, Derakhshan AA, Influence of process and operating variables on the performance and fouling behavior of modified nanofiltration membranes treating licorice aqueous solution, Journal of Applied Research in Water and Wastewater, (2019)

38. Orooji Y, Liang F, Razmjou A, Li S, Mofid MR, Liu Q, Guan K, Liu Z, Jin W (2017) Excellent biofouling alleviation of thermoexfoliated vermiculite blended poly (ether sulfone) ultrafiltration membrane. ACS Appl Mater Interfaces 9:30024-30034

39. Long Q, Zhang Z, Qi G, Wang Z, Chen Y, Liu Z-Q (2020) Fabrication of Chitosan Nanofiltration Membranes by the Film Casting Strategy for Effective Removal of Dyes/Salts in Textile Wastewater. ACS Sustainable Chemistry Engineering 8:2512-2522

40. Huang S, Wu M-B, Zhu C-Y, Ma M-Q, Yang J, Wu J, Xu Z-K (2019) Polyamide nanofiltration membranes incorporated with cellulose nanocrystals for enhanced water flux and chlorine resistance. ACS Sustainable Chemistry Engineering 7:12315-12322

41. Long Q, Qi G, Wang Y (2015) Synthesis and application of ethylenediamine tetrapropionic salt as a novel draw solute for forward osmosis application. AIChE J 61:1309-1321

42. Guo D, Xiao Y, Li T, Zhou Q, Shen L, Li R, Xu Y, Lin H (2020) Fabrication of high-performance composite nanofiltration membranes for dye wastewater treatment: mussel-inspired layer-by-layer self-assembly. J Colloid Interface Sci 560:273-283

43. Yu W, Liu Y, Xu Y, Li R, Chen J, Liao B-Q, Shen L, Lin H (2019) A conductive PVDF-Ni membrane with superior rejection, permeance and antifouling ability via electric assisted in-situ aeration for dye separation. J Membr Sci 581:401-412

44. Zhao Y, Yu W, Li R, Xu Y, Liu Y, Sun T, Shen L, Lin H (2019) Electric field endowing the conductive polyvinylidene fluoride (PVDF)-graphene oxide (GO)-nickel (Ni) membrane with high-efficient performance for dye wastewater treatment. Appl Surf Sci 483:1006-1016

45. Begonja S, Rodenas LG, Borghi E, Morando P (2012) Adsorption of cysteine on TiO2 at different pH values: Surface complexes characterization by FTIR-ATR and Langmuir isotherms analysis. Colloids Surf A 403:114-120

46. El Ibrahimi B, Jmiai A, Somoue A, Oukhrib R, Chadili M, El Issami S, Bazzi L (2018) Cysteine duality effect on the corrosion inhibition and acceleration of 3003 aluminium alloy in a $2 \% \mathrm{NaCl}$ solution. 
Portugaliae Electrochimica Acta 36:403-422

47. Hairom NHH, Mohammad AW, Kadhum AAH (2014) Nanofiltration of hazardous Congo red dye: performance and flux decline analysis. Journal of Water Process Engineering 4:99-106

48. Hu R, He Y, Zhang C, Zhang R, Li J, Zhu H (2017) Graphene oxide-embedded polyamide nanofiltration membranes for selective ion separation. Journal of Materials Chemistry A 5:25632-25640

49. Wang X-I, Qin W, Wang L-x, Zhao K-y, Wang H-c (2020) H.-y. Liu, J.-f. Wei, Desalination of dye utilizing carboxylated $\mathrm{TiO} 2 /$ calcium alginate hydrogel nanofiltration membrane with high salt permeation. Sep Purif Technol 253:117475

50. Chen P, Ma X, Zhong Z, Zhang F, Xing W, Fan Y, Performance of ceramic nanofiltration membrane for desalination of dye solutions containing $\mathrm{NaCl}$ and Na2SO4, Desalination, 404 (2017) 102-111

51. Rambabu K, Bharath G, Monash P, Velu S, Banat F, Naushad M, Arthanareeswaran G, Show PL (2019) Effective treatment of dye polluted wastewater using nanoporous $\mathrm{CaCl} 2$ modified polyethersulfone membrane. Process Saf Environ Prot 124:266-278

\section{Figures}
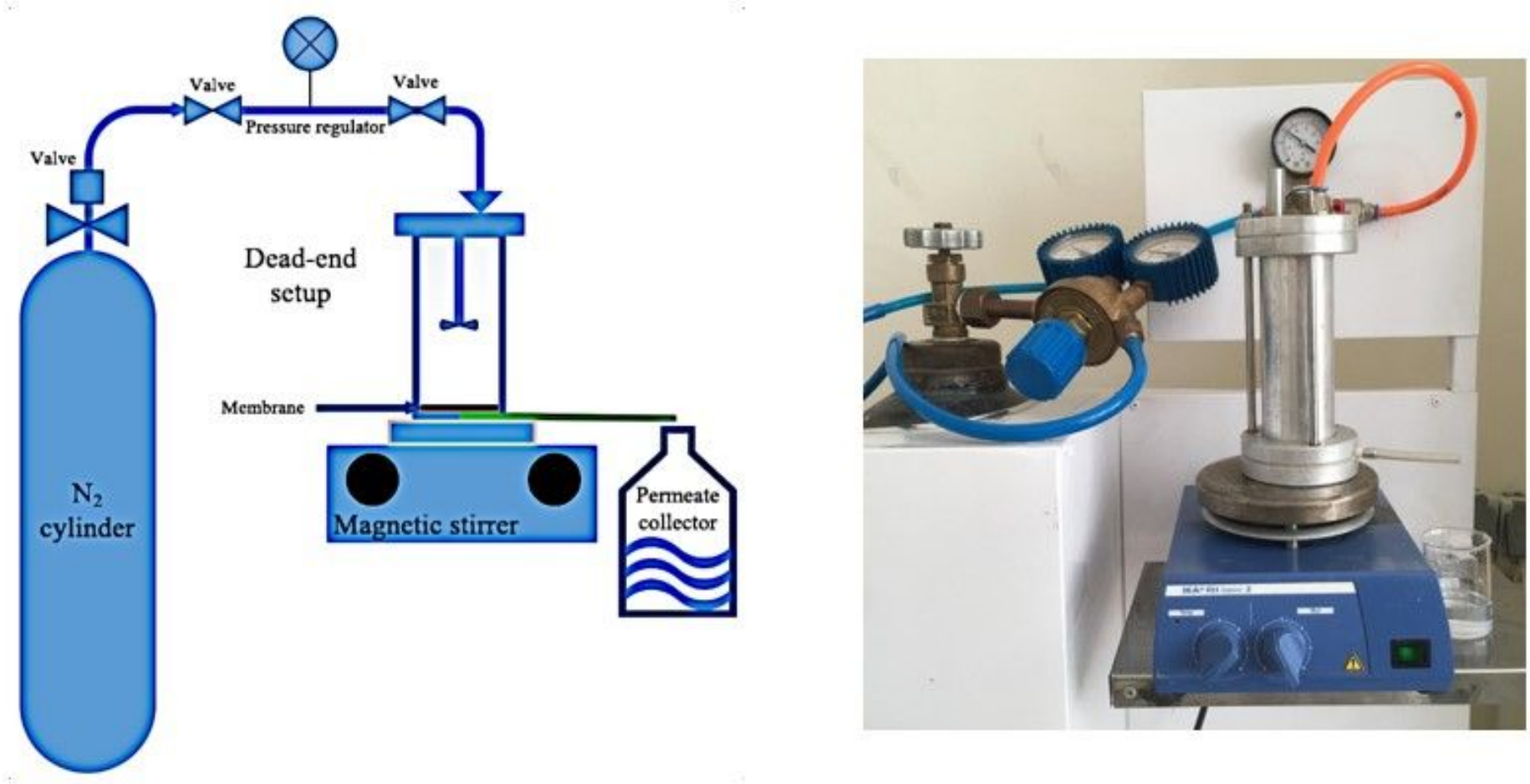

\section{Figure 1}

Schematic of the dead-end setup. 


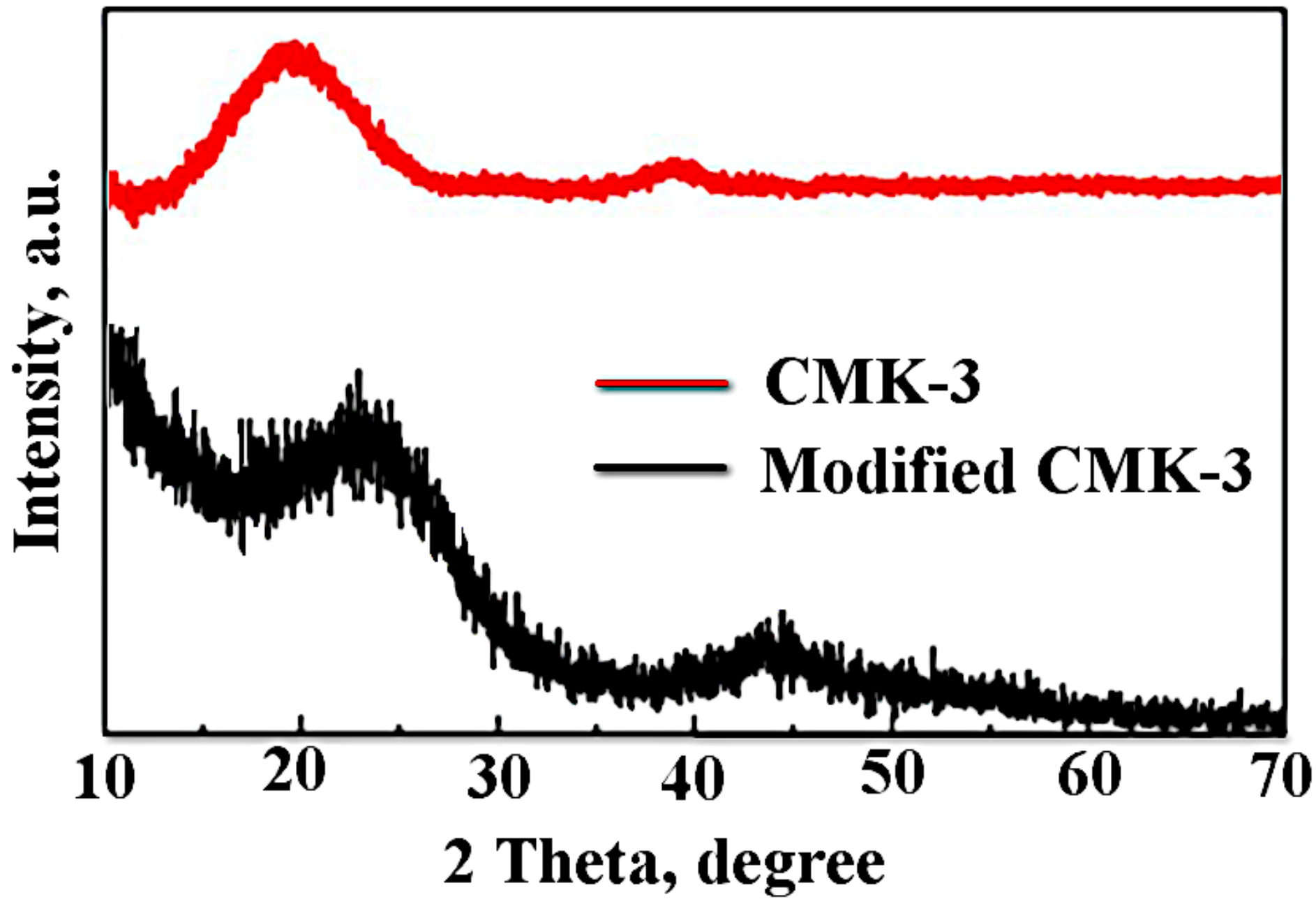

Figure 2

XRD pattern of CMK-3 and M-CMK-3. 


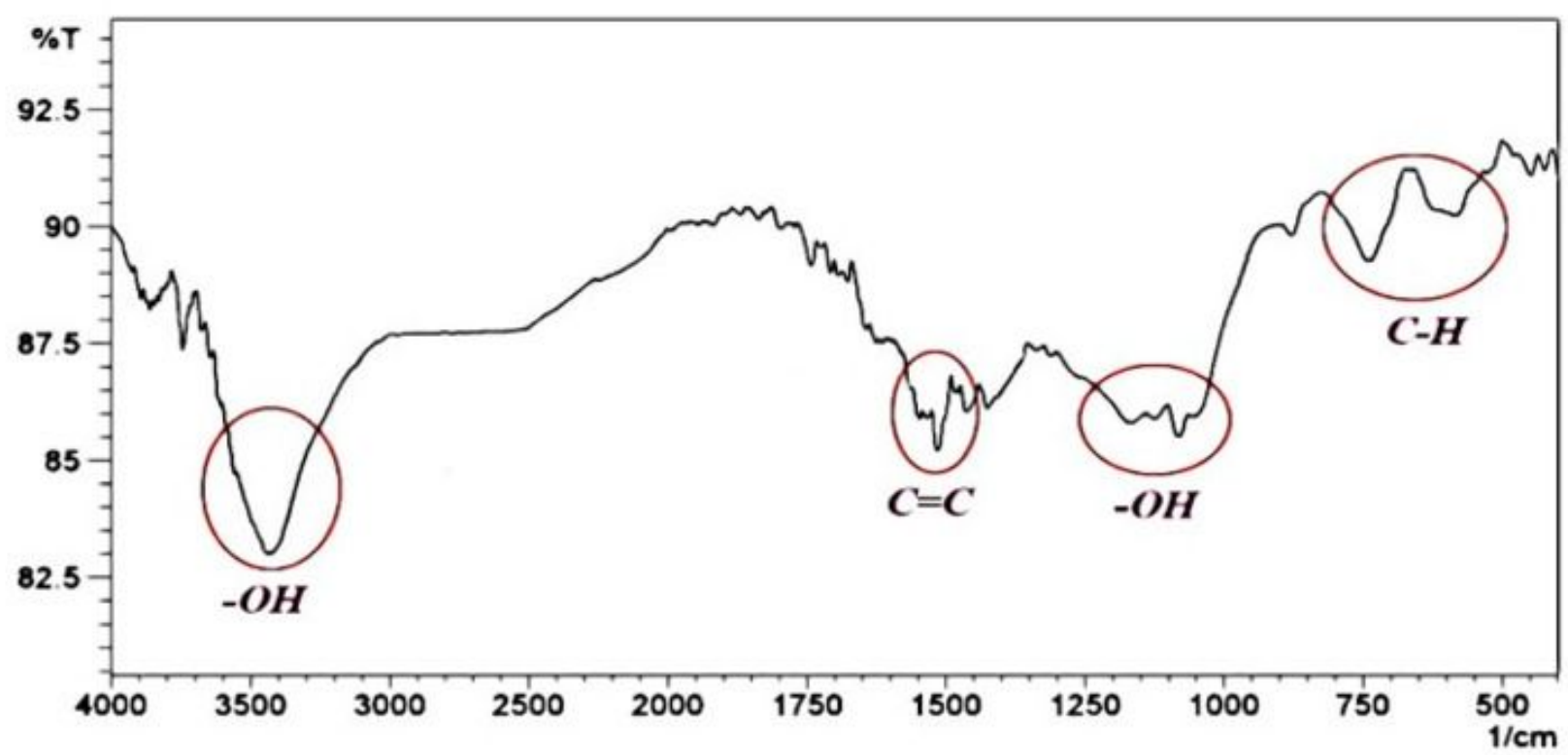

(a)

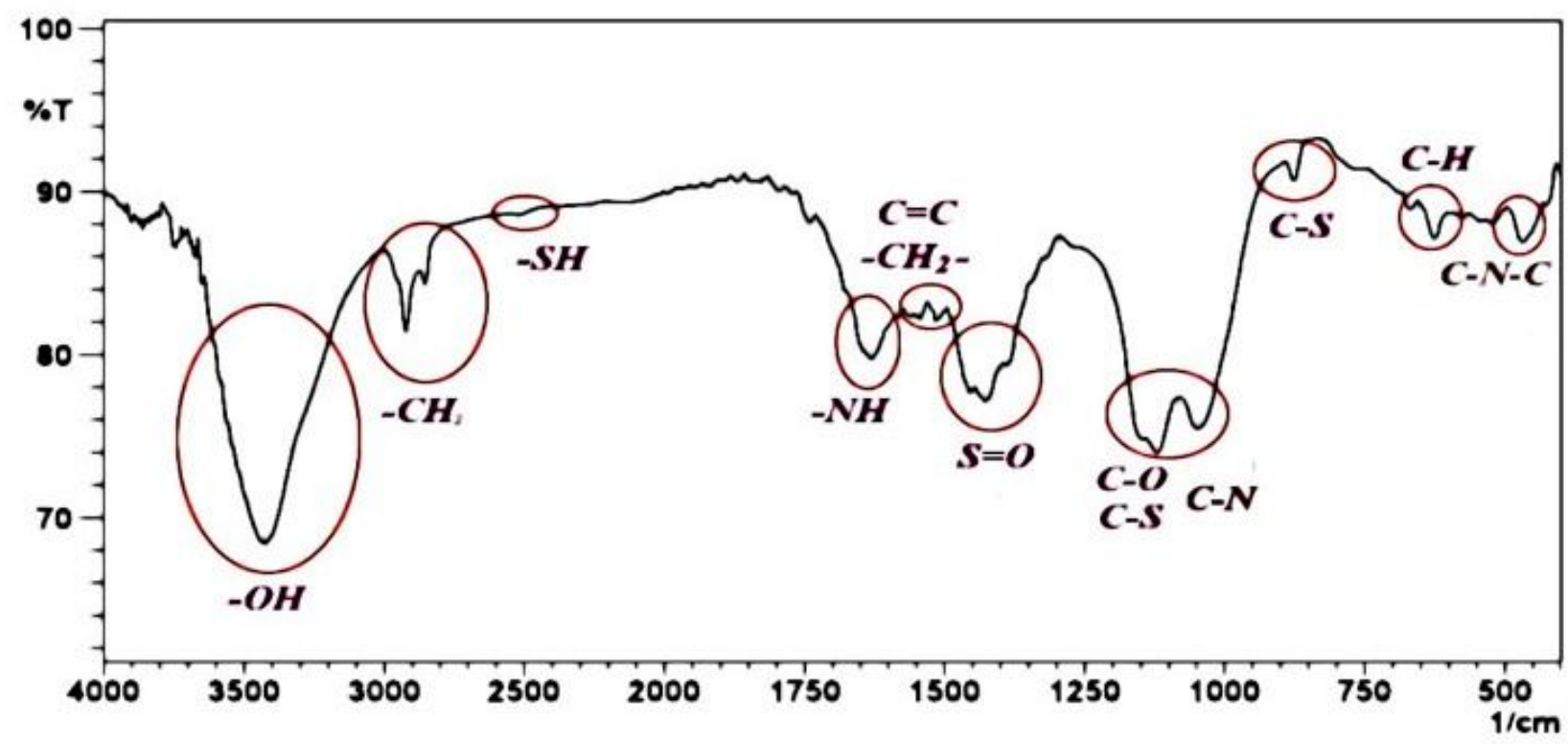

(b)

Figure 3

FT-IR spectrum of CMK-3 (a) and M-CMK-3 (b). 


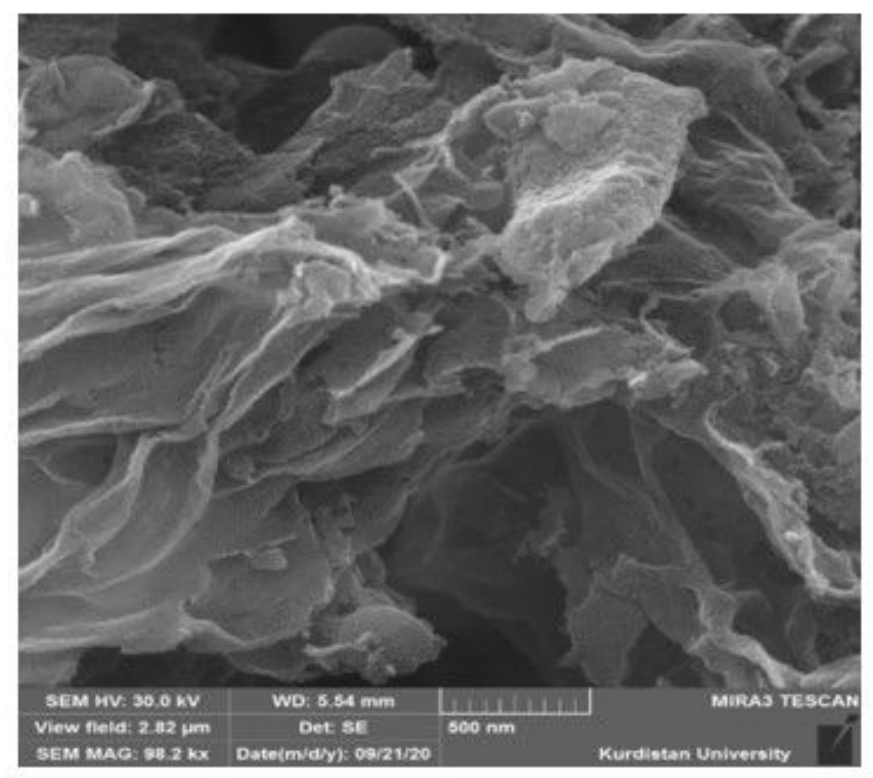

(a)

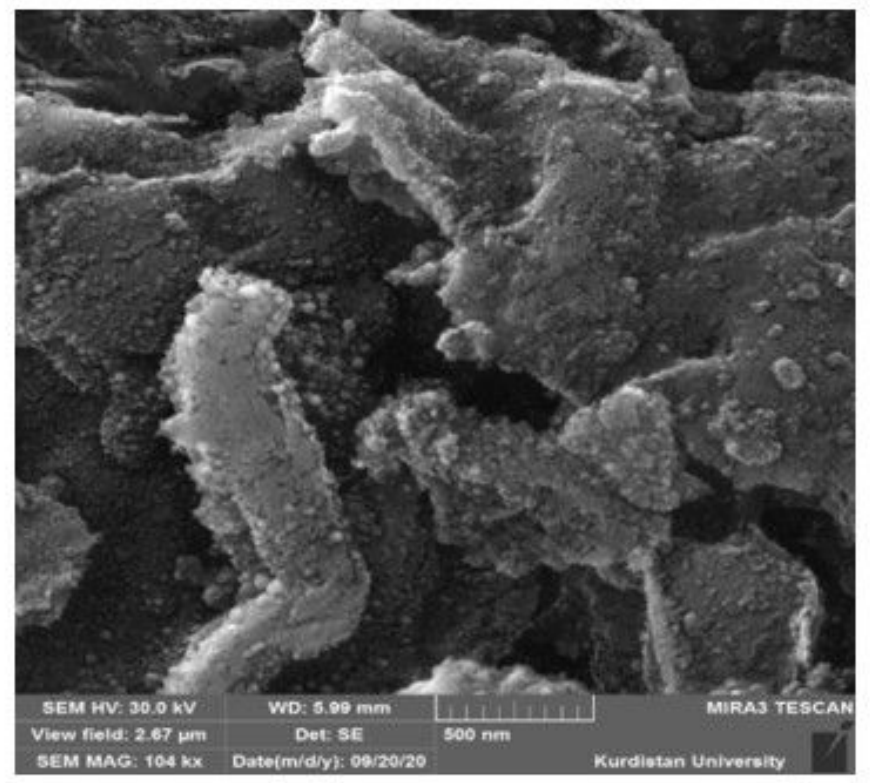

(b)

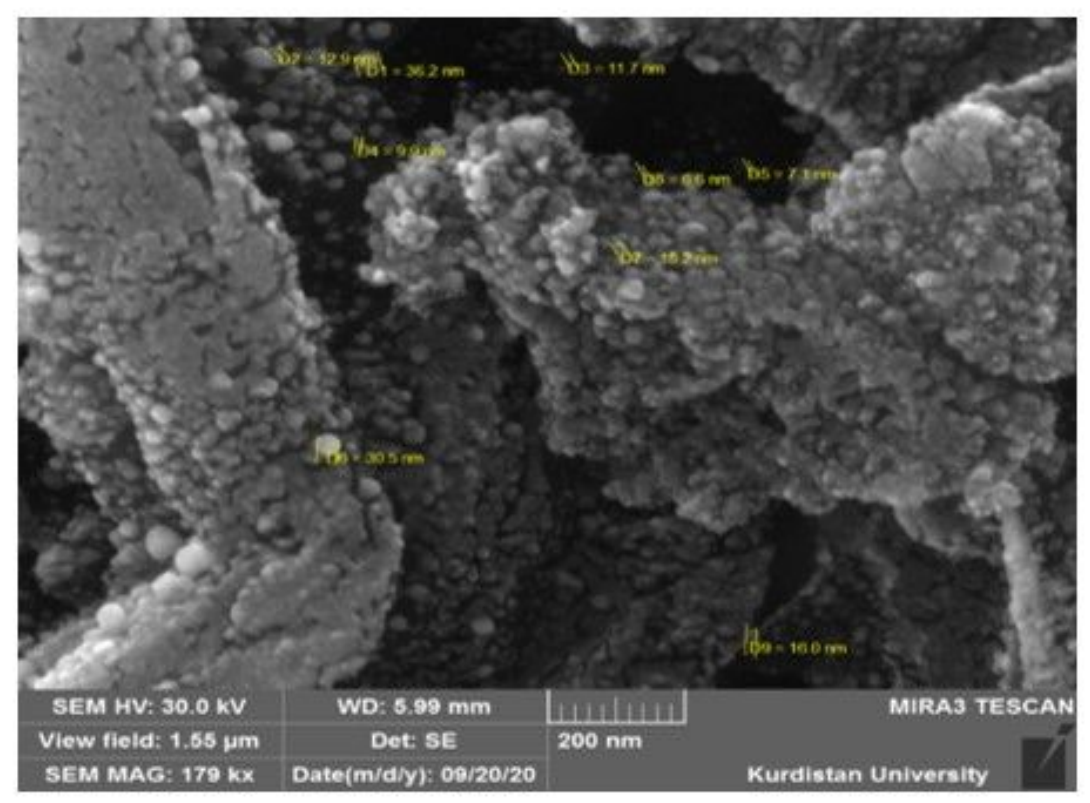

(c)

\section{Figure 4}

SEM images of CMK-3 (a) M-CMK-3 (b) and size distribution of M-CMK-3. 


\section{Zeta Potential Distribution}

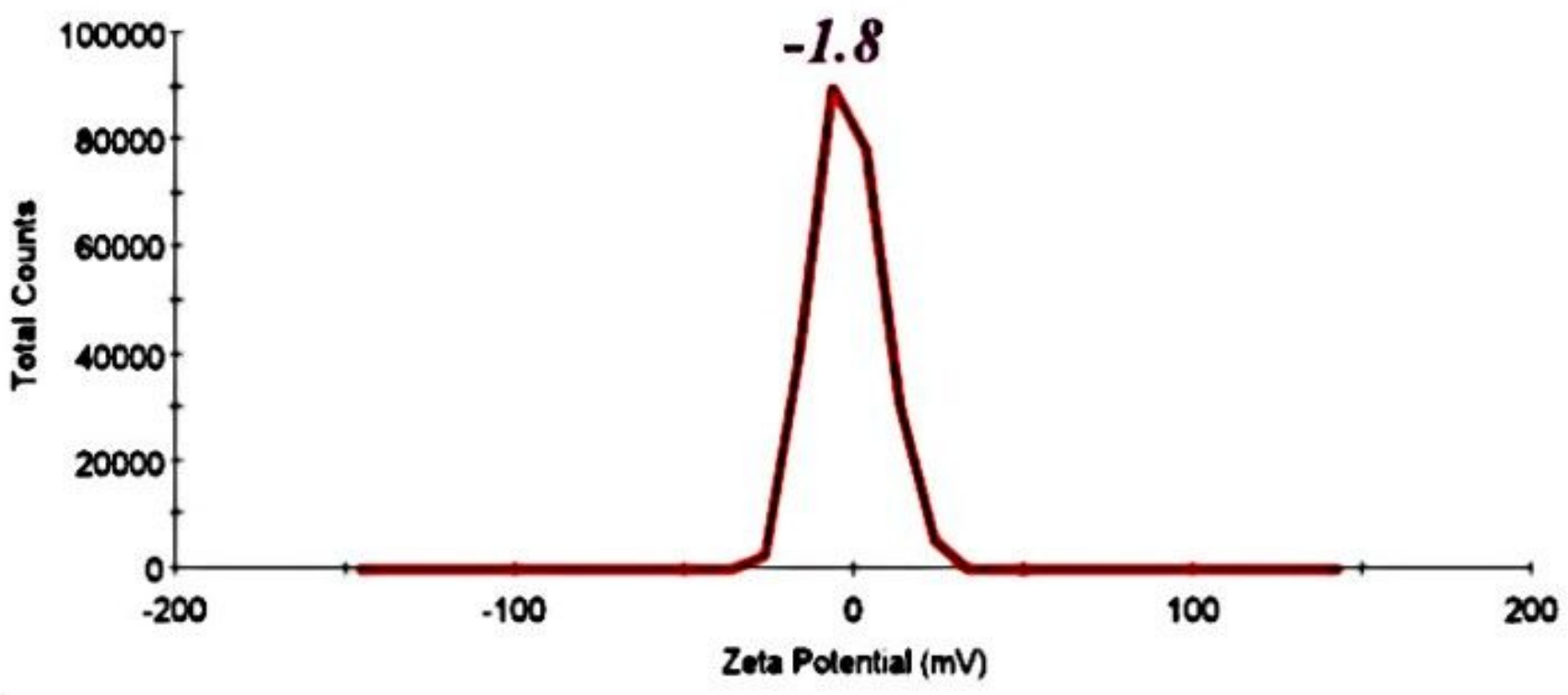

(a)

Zeta Potential Distribution

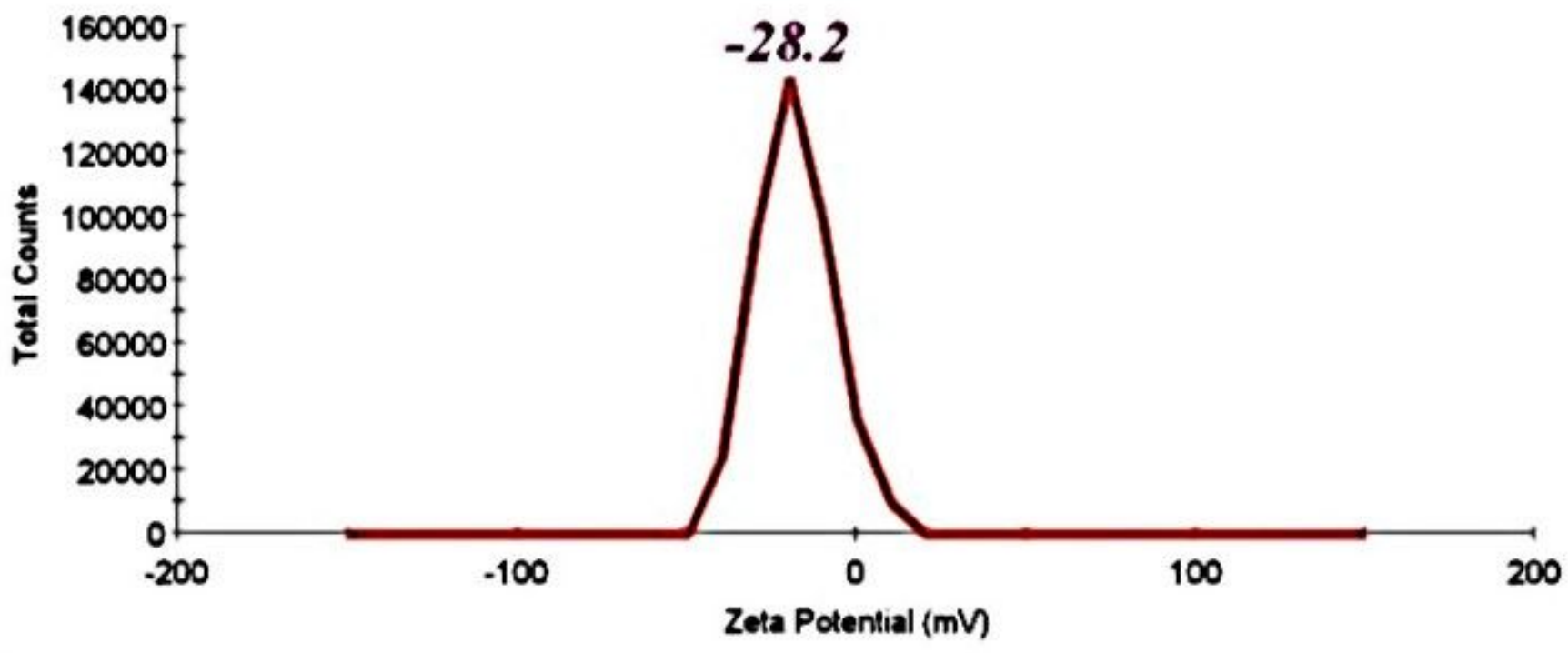

(b)

Figure 5

Zeta potential of a) CMK-3 and b) M-CMK-3. 


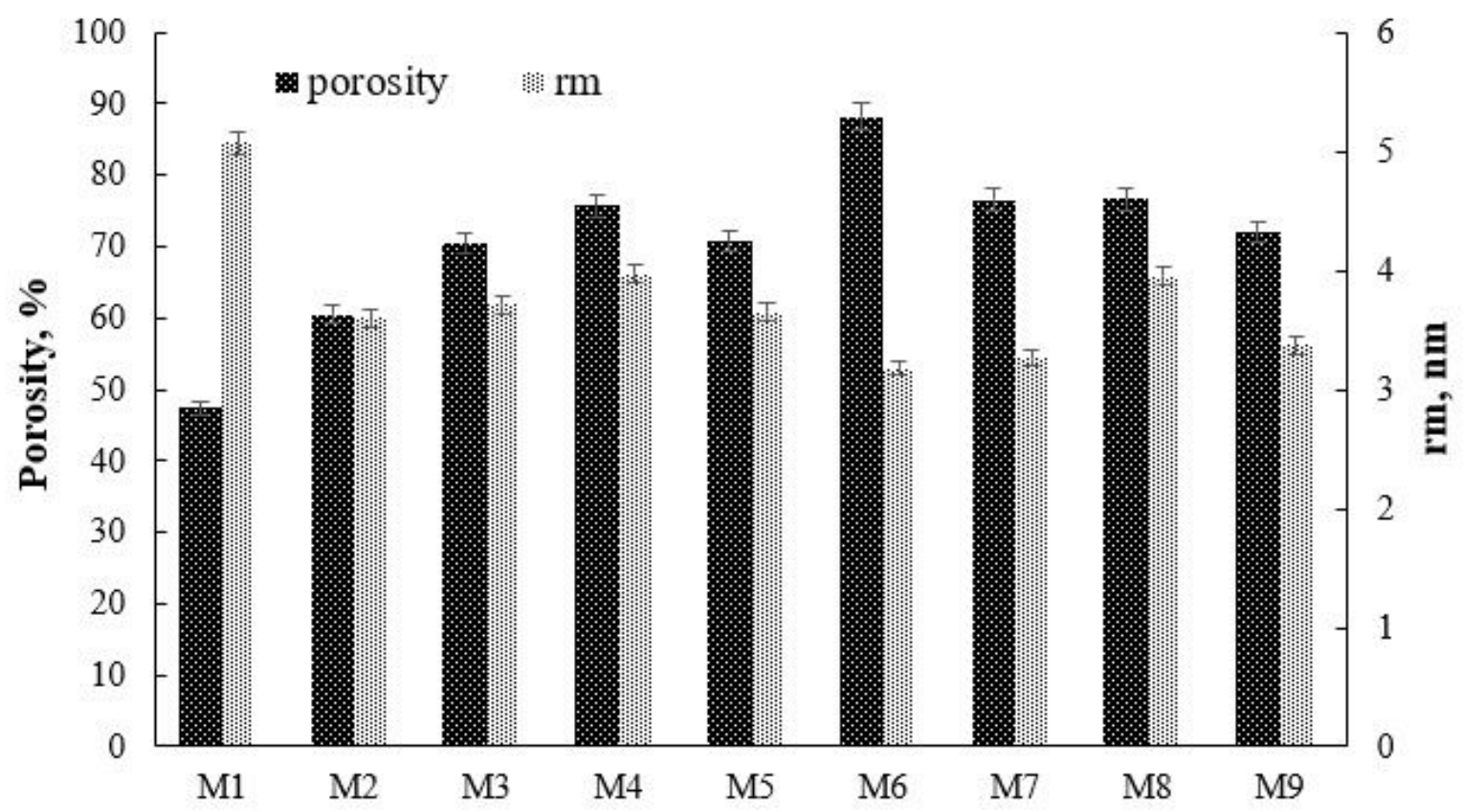

(a)

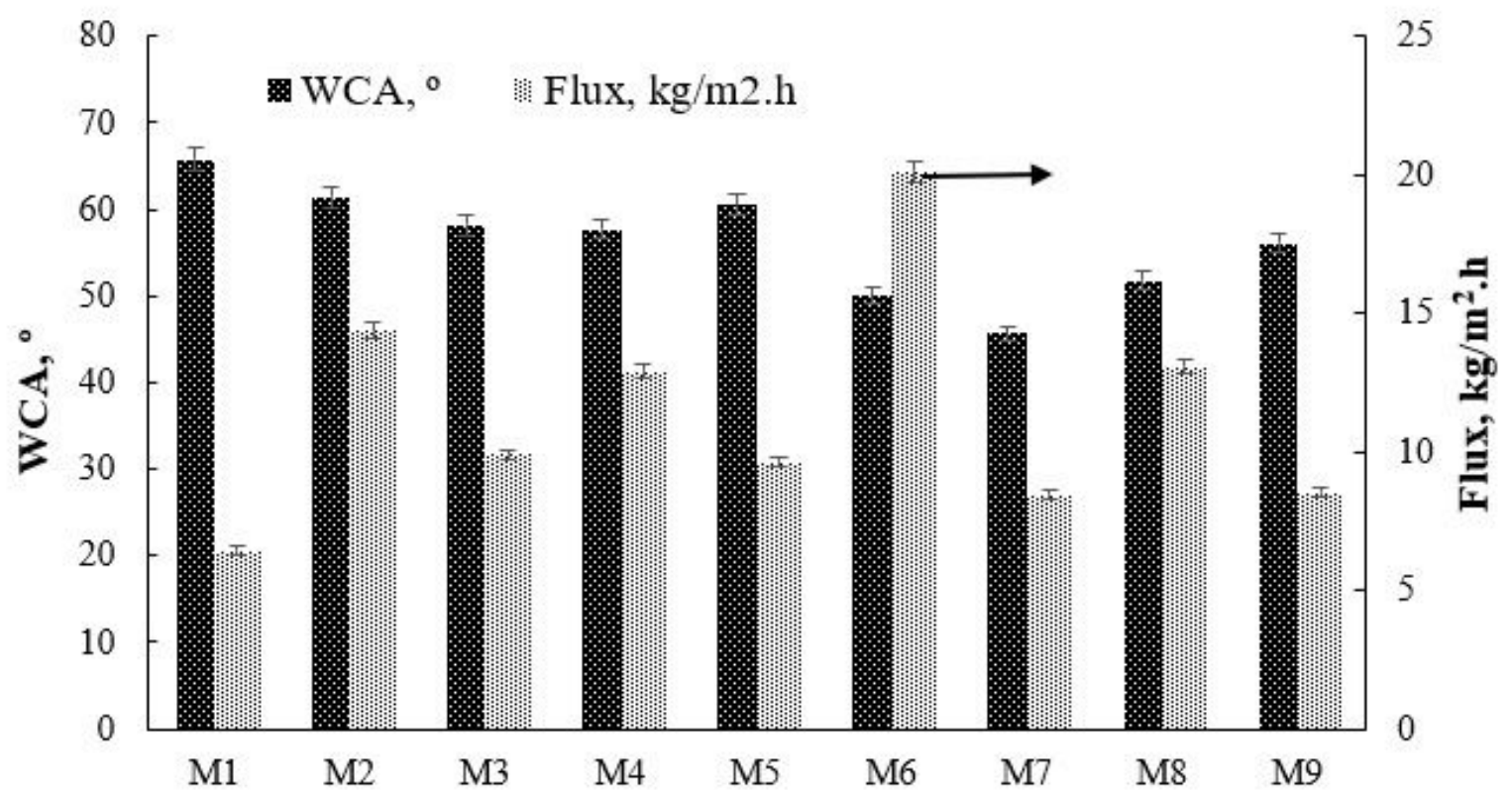

(b)

Figure 6

Porosity and rm of the prepared membranes (a), WCA and pure water flux of the prepared membranes (b). 


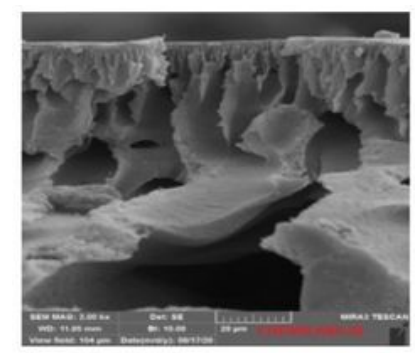

Mn

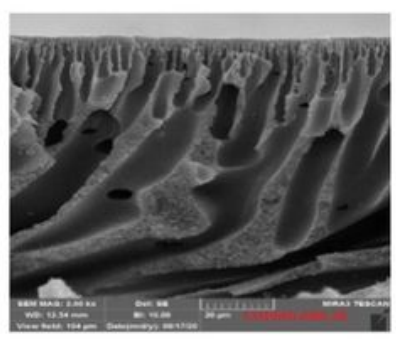

M3

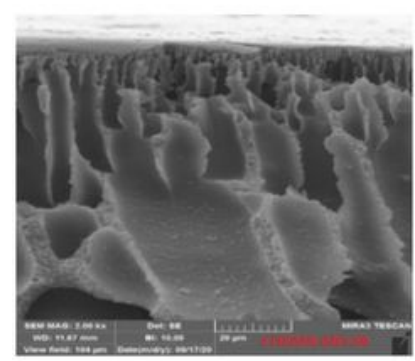

M5

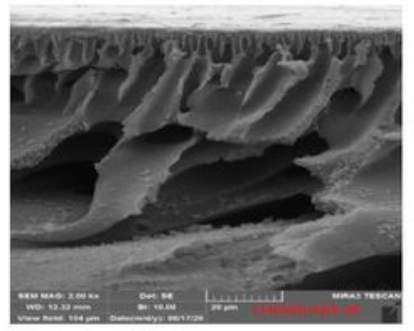

M7

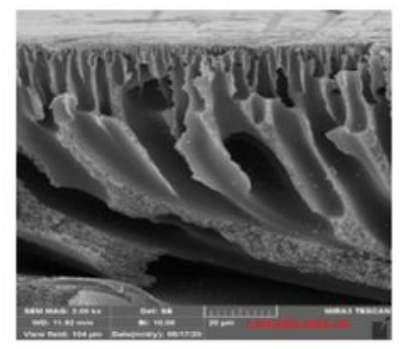

M2

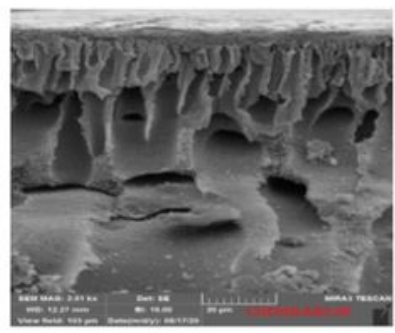

M4

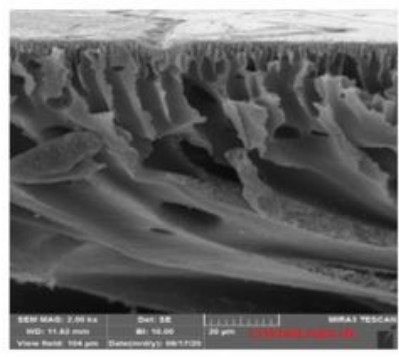

M6

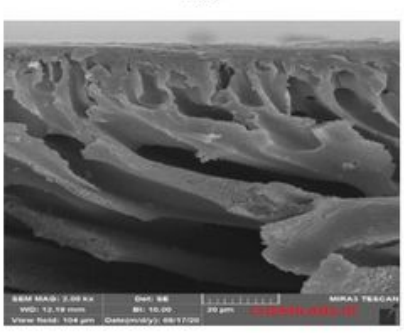

M8

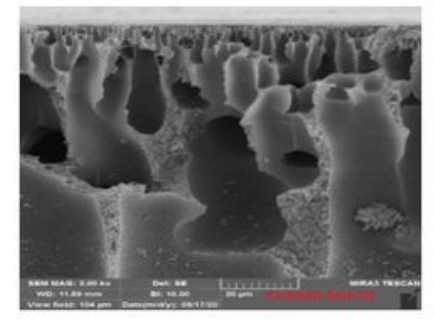

M9

Figure 7

Cross-section SEM images of the prepared membrane. 


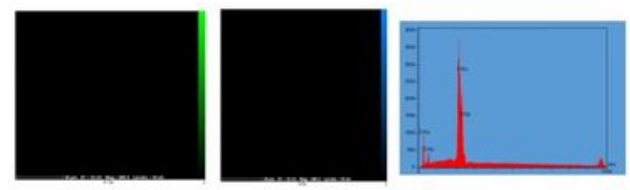

M

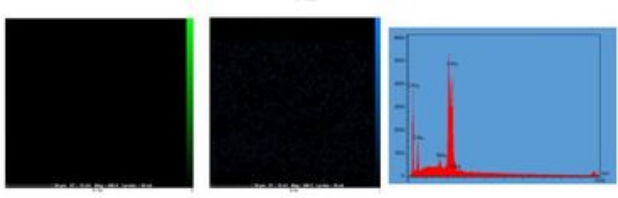

an

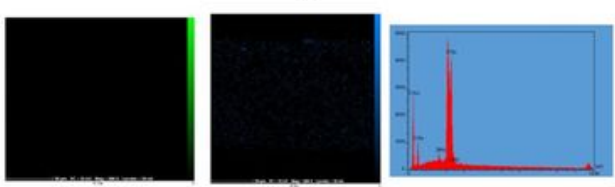

M

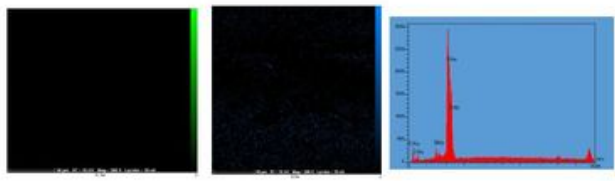

$\mathrm{M}$

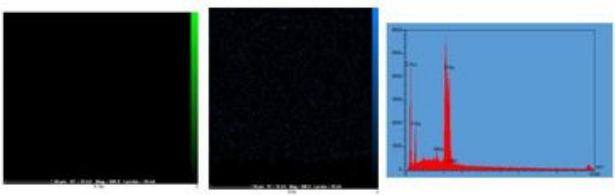

Ms
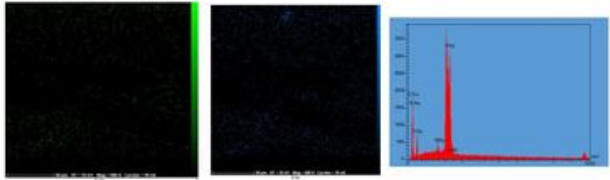

M6
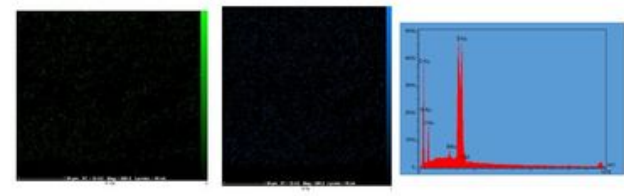

$\mathrm{s}$
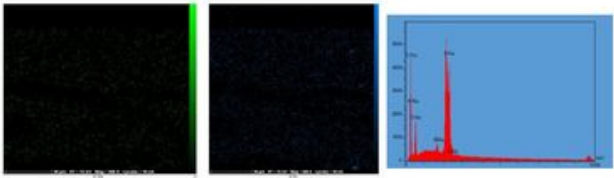

Ms
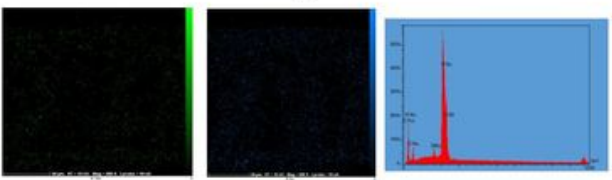

M9

Figure 8

EDX and EDX mapping images of the prepared membrane (green) for silicon element, (blue) for nitrogen element 


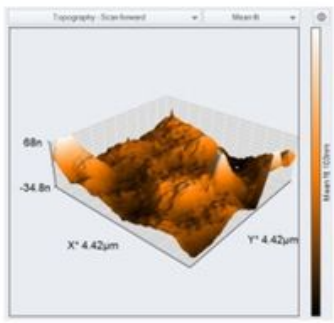

Mn

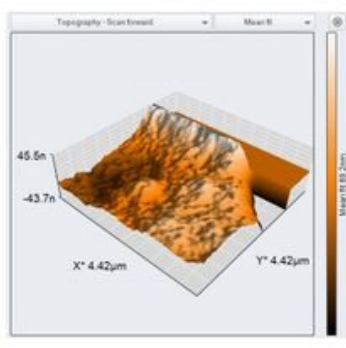

M13

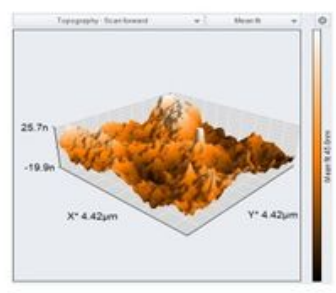

M5

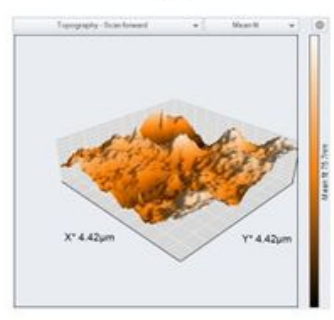

M7

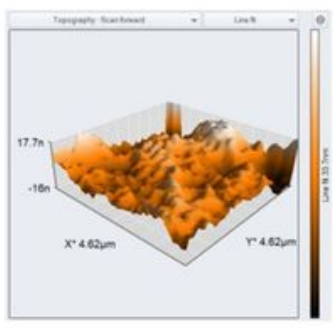

M2

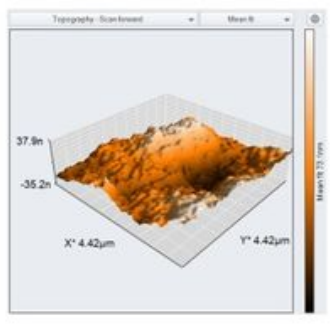

M4

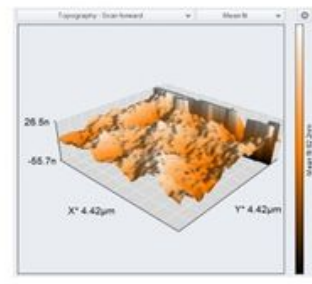

M6

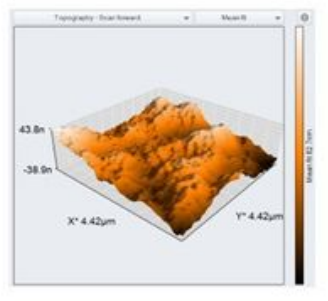

Ms

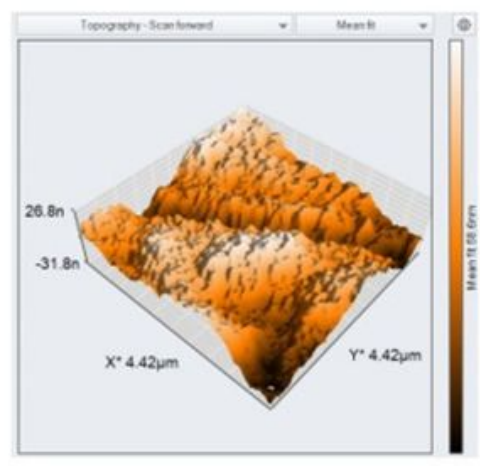

M9

Figure 9

AFM images of the prepared membranes. 


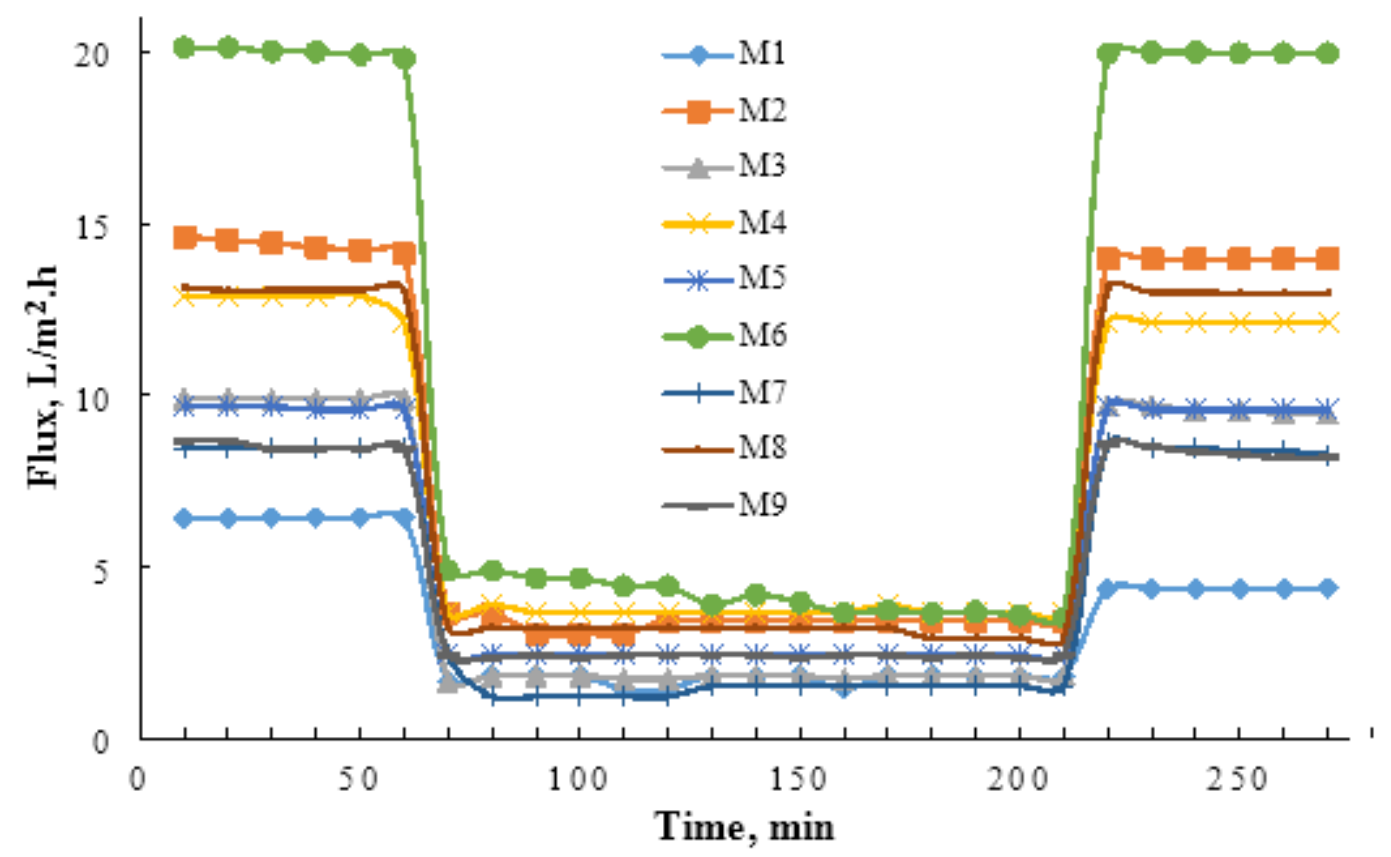

Figure 10

Fouling behavior for the prepared membranes in three steps. 


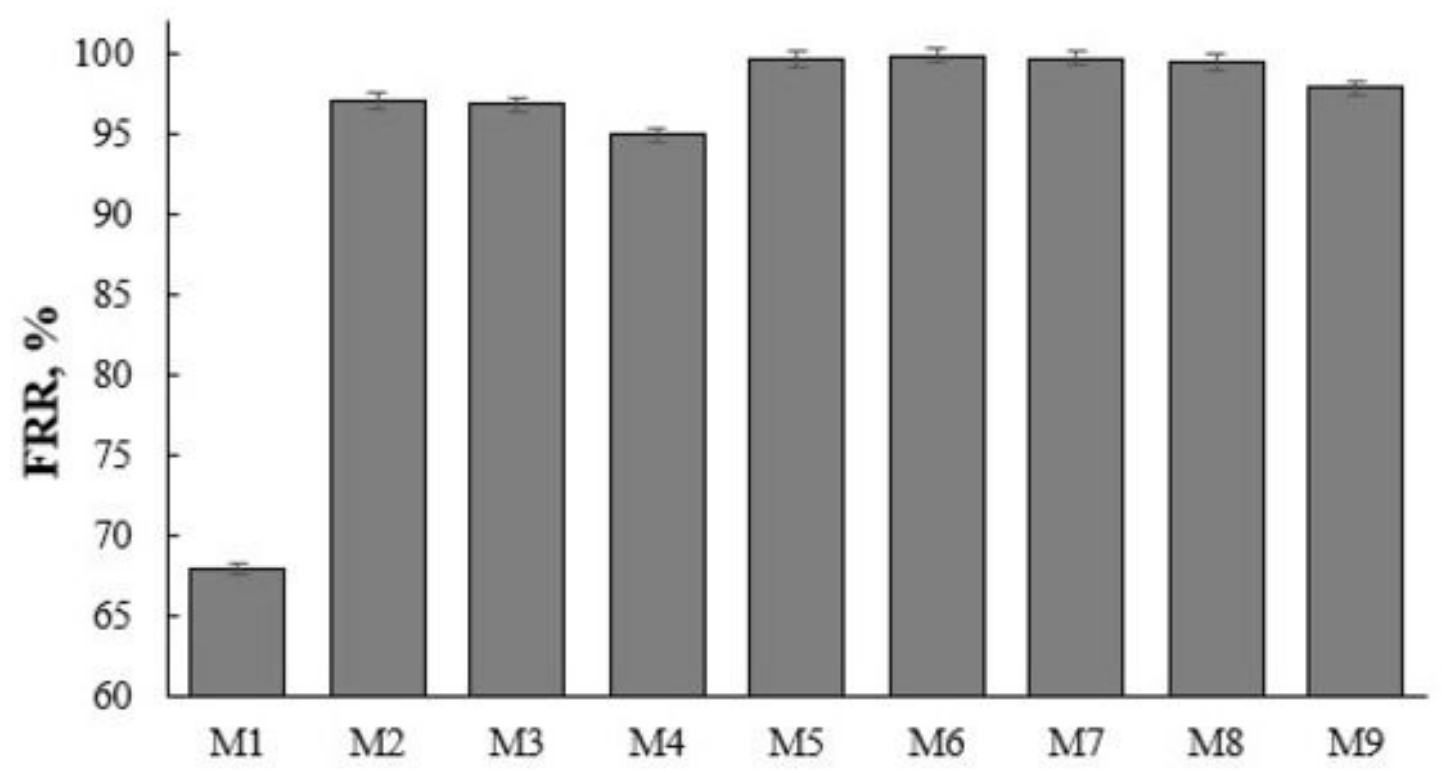

(a)

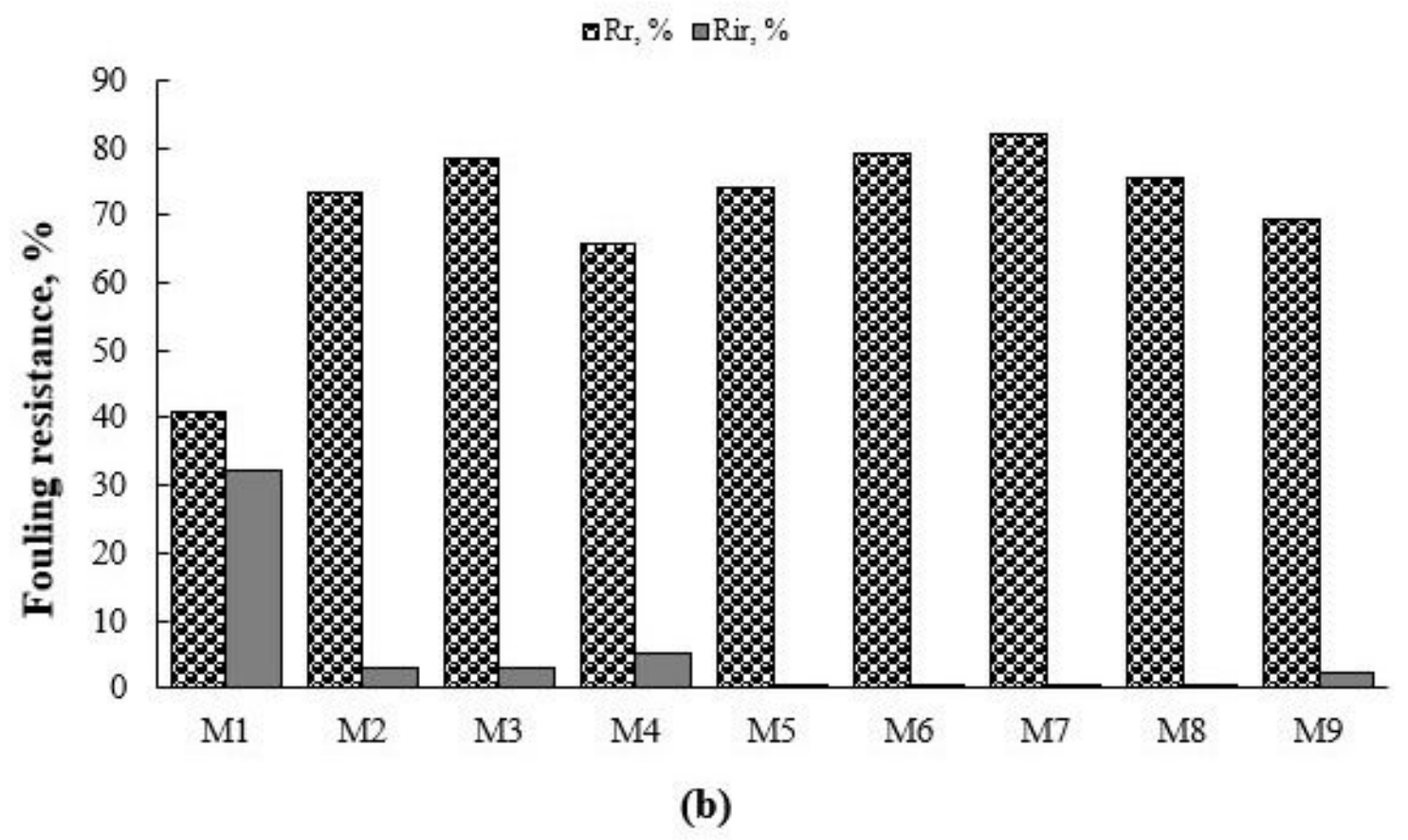

Figure 11

(a) The flux recovery ratio (FRR) and (b) fouling resistance (Rr and Rir) for the prepared membranes. 


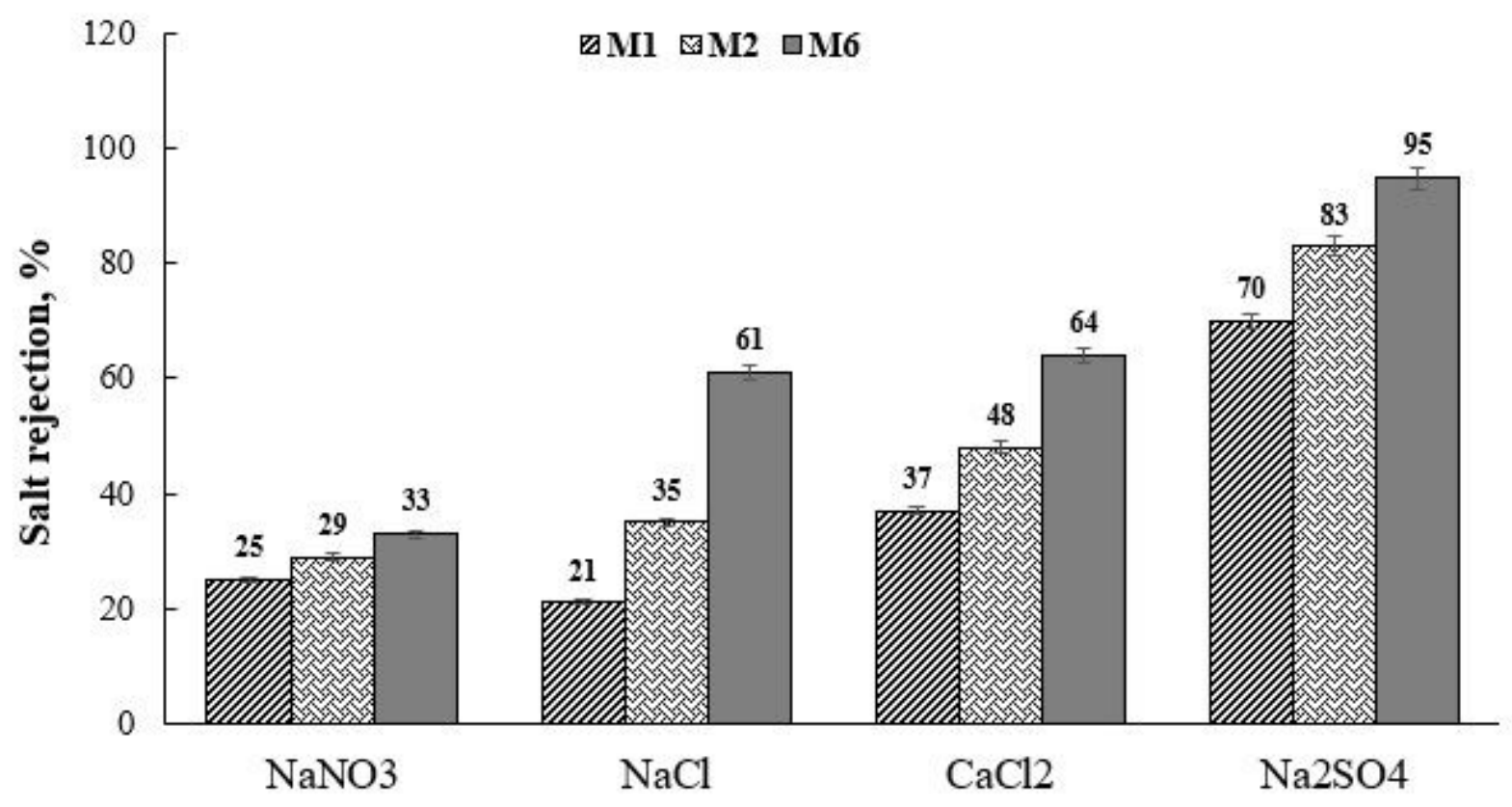

(a)

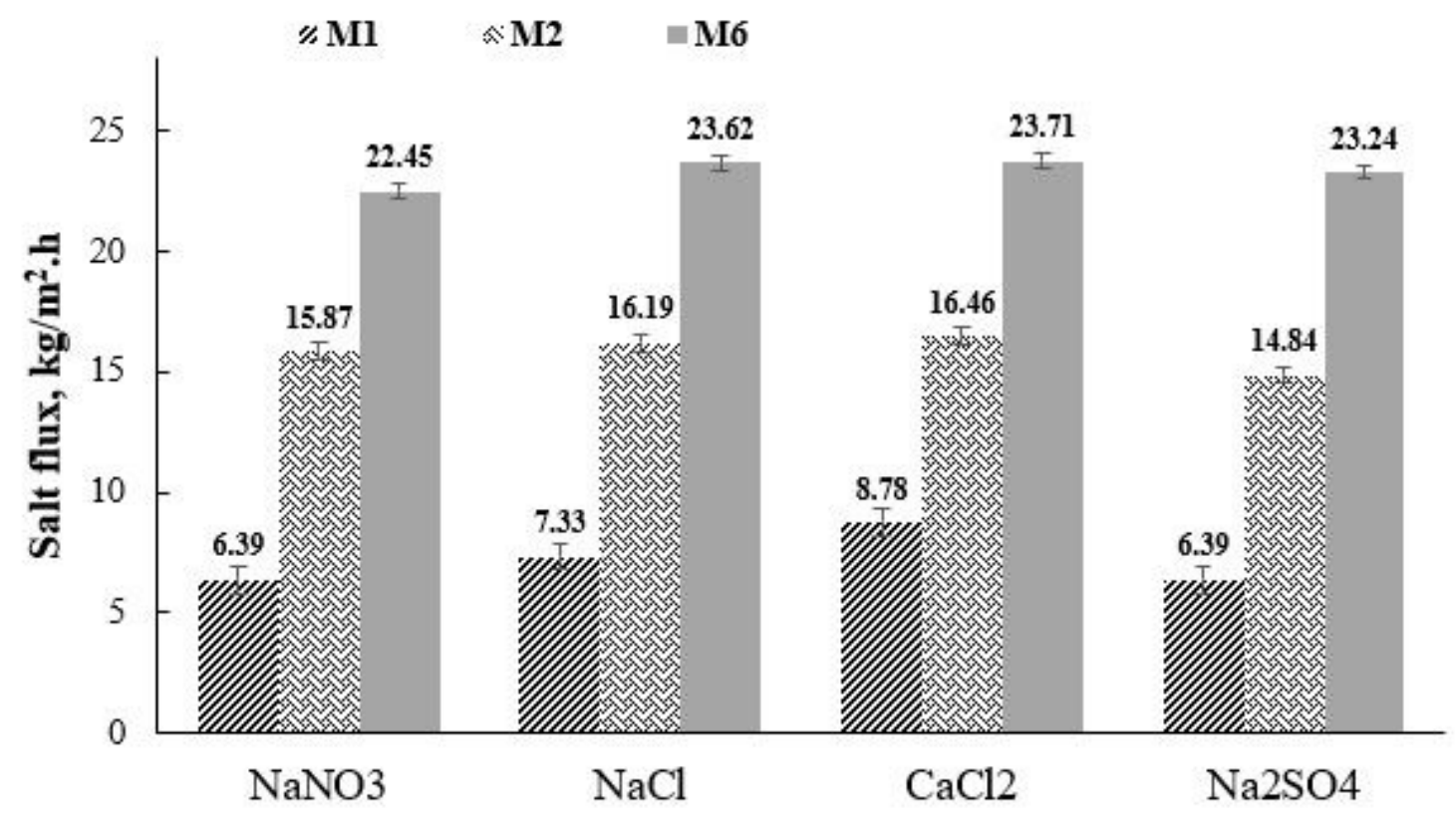

(b)

\section{Figure 12}

Separation performance for inorganic salts with concentration of $5 \mathrm{mM}(\mathrm{Na} 2 \mathrm{SO} 4, \mathrm{NaNO} 3, \mathrm{NaCl}$ and $\mathrm{CaCl} 2)(\mathrm{a})$ salts rejection and (b) water flux of series of $\mathrm{M} 1, \mathrm{M} 2$ and $\mathrm{M} 6$ membranes at 4 bar. 


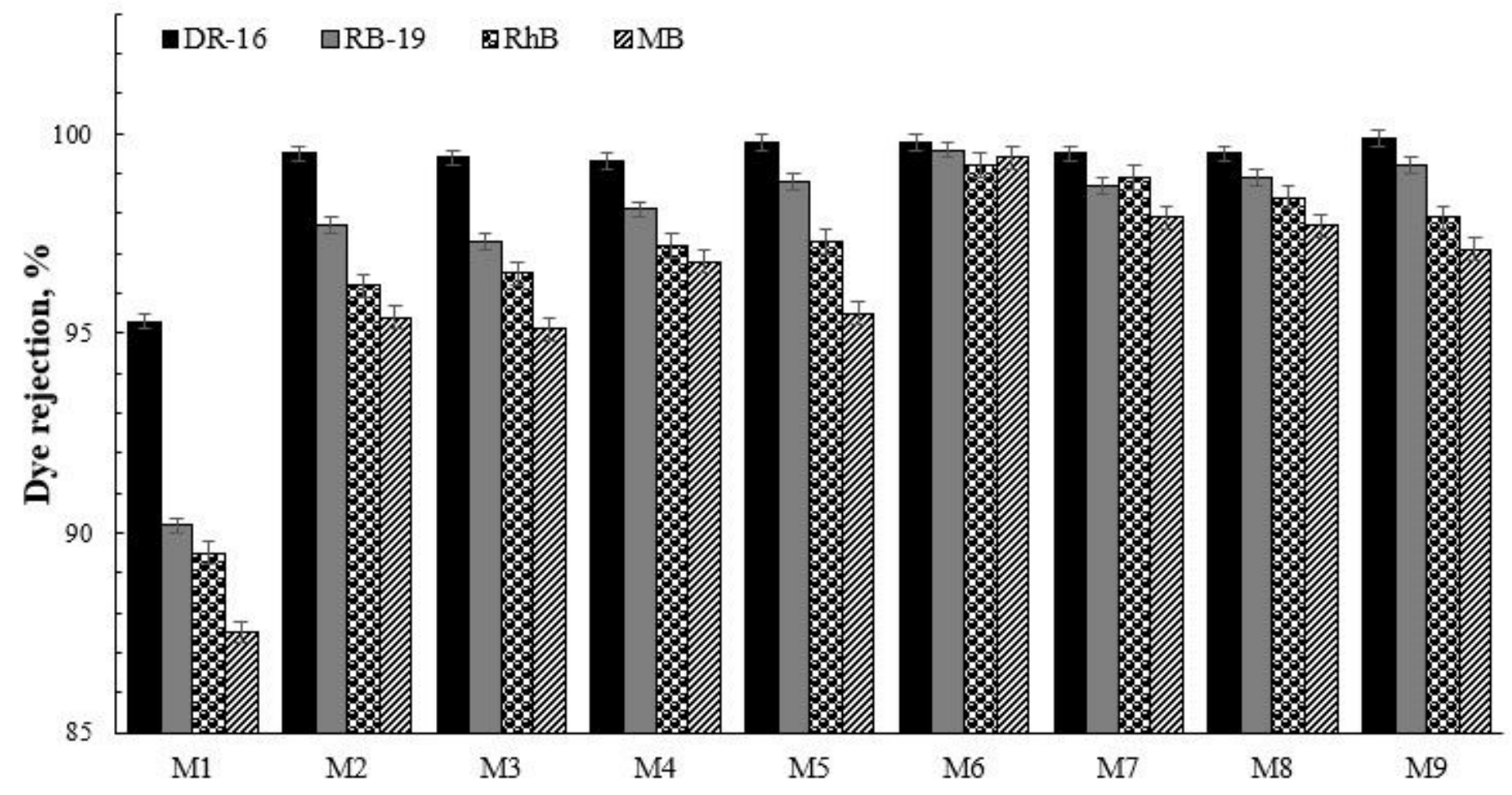

Figure 13

Dye rejection of all membranes synthesized for different dyes (30ppm). 


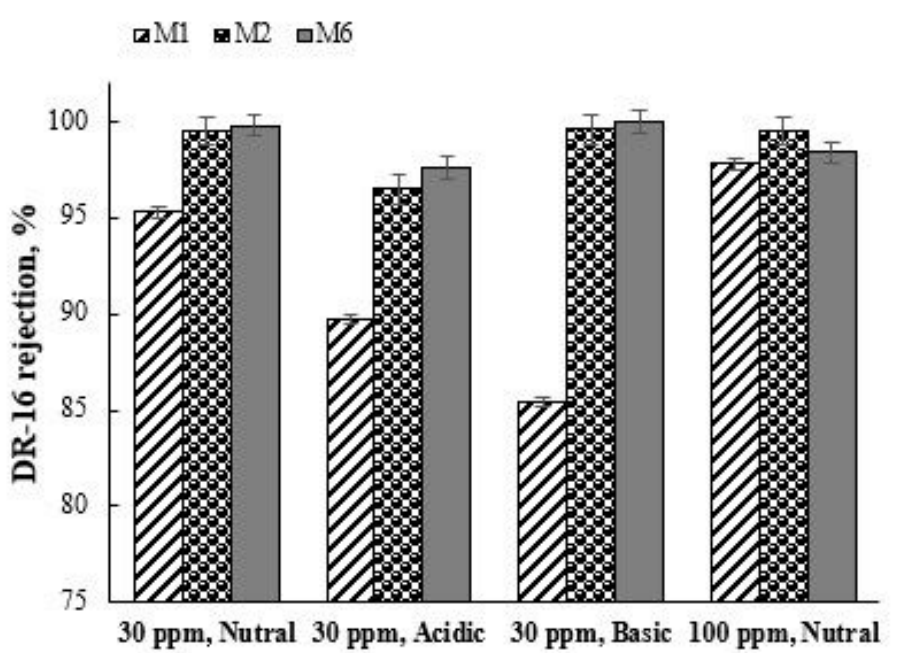

(a)

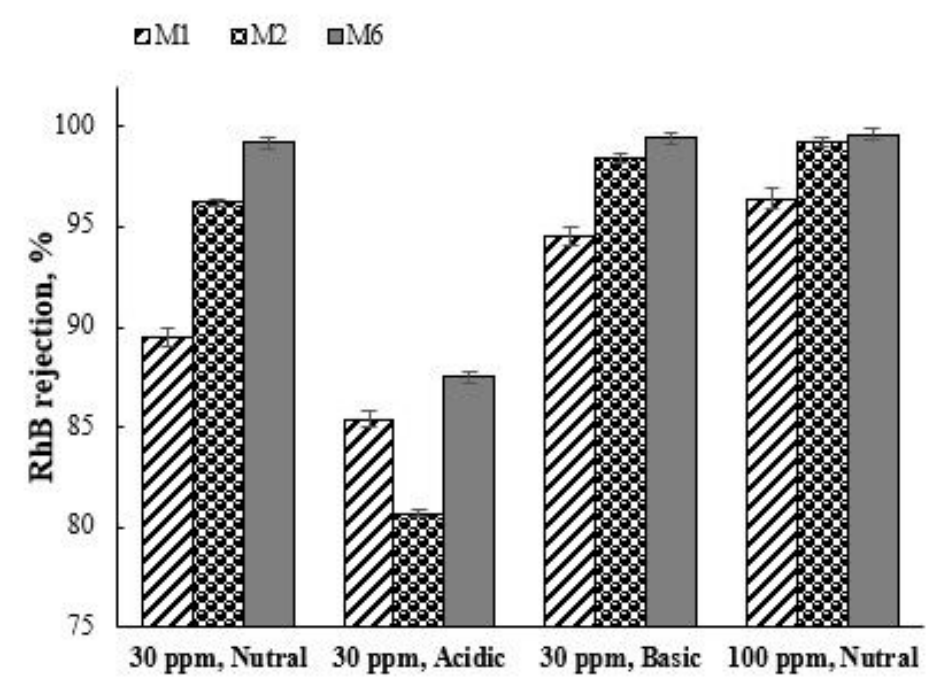

(c)

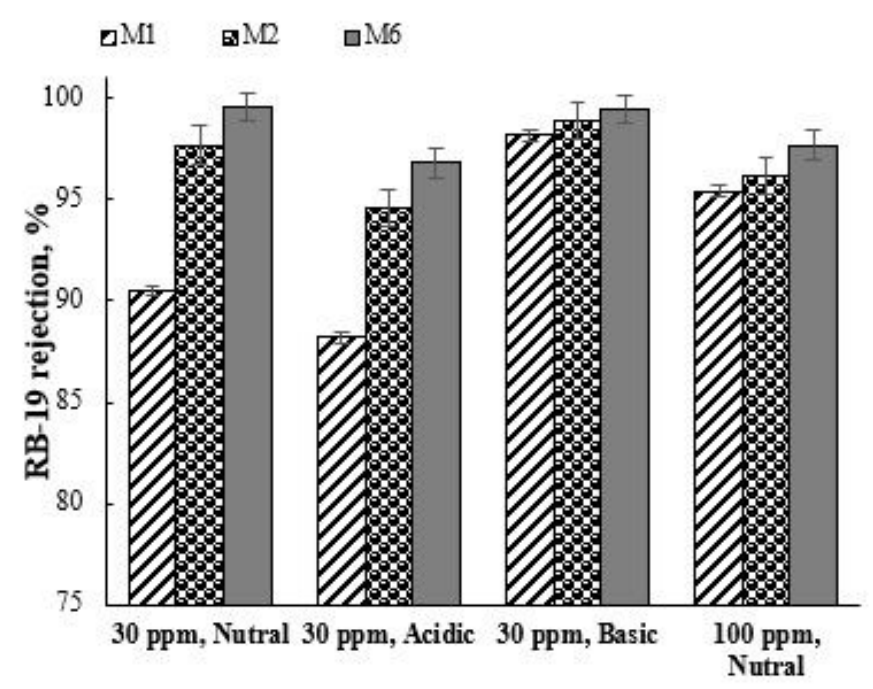

(b)

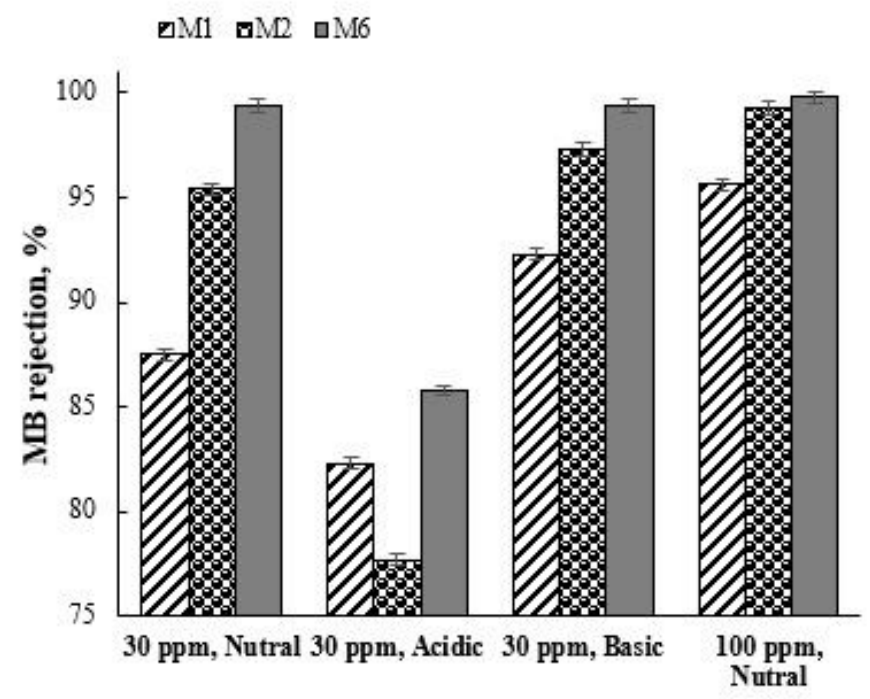

(d)

\section{Figure 14}

Dye rejection of bare (M1) and optimal (M2 and M6) membranes at different $\mathrm{pH}$ for all dyes. 


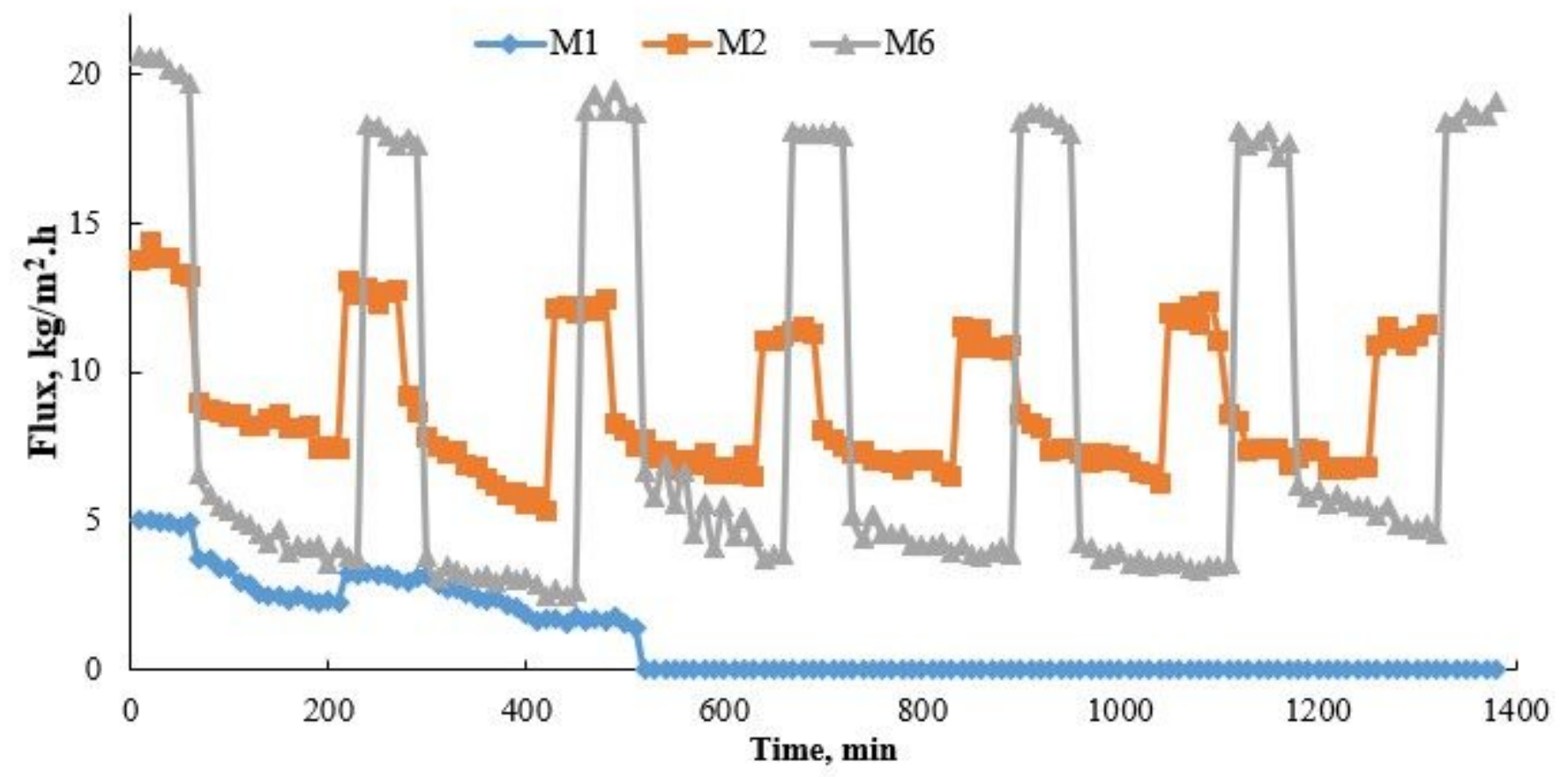

Figure 15

The long-term performance of the selected membranes. 